Journal of Economics and Management Strategy, 6:3, 431-495, 1997.

\title{
The FCC Spectrum Auctions: An Early Assessment
}

\author{
Peter C. Cramton* \\ University of Maryland
}

\begin{abstract}
This paper analyzes six spectrum auctions conducted by the Federal Communications Commission (FCC) from July 1994 to May 1996. These auctions were simultaneous multipleround auctions in which collections of licenses were auctioned simultaneously. This auction form proved remarkably successful. Similar items sold for similar prices and bidders successfully formed efficient aggregations of licenses. Bidding behavior differed substantially in the auctions. The extent of bidder competition and price uncertainty played an important role in determining behavior. Bidding credits and installment payments also played a major role in several of the auctions.
\end{abstract}

JEL No.: D44 (Auctions), L96 (Telecommunications)

Keywords: Auctions, Multi-Object Auctions, Spectrum Auctions

Send comments to:

Professor Peter C. Cramton

Department of Economics

University of Maryland

College Park, MD 20742-7211

email: cramton@umd.edu phone: (301) 405-6987

*I am grateful to the National Science Foundation for funding. I served as an auction advisor to several firms (PageNet, MCI, and DCR Communications) and the FCC during this period. The views expressed are my own. I thank Larry Ausubel, Ian Ayres, David Moore, Bob Rosenthal, Greg Rosston, David Salant, and seminar participants for helpful comments. I am especially grateful to Evan Kwerel for many insights and comments. 


\title{
The FCC Spectrum Auctions: An Early Assessment
}

\author{
Table of Contents
}

1 Introduction 1

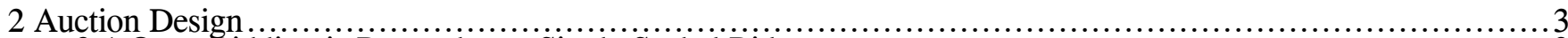

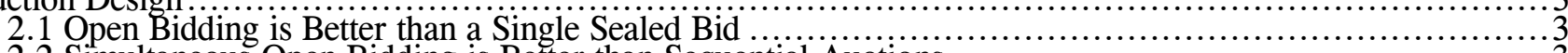

2.2 Simultaneous Open Bidding is Better than Sequential Auctions ….....................................................

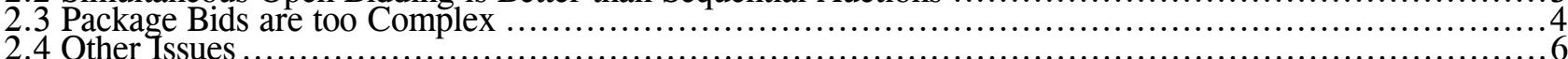

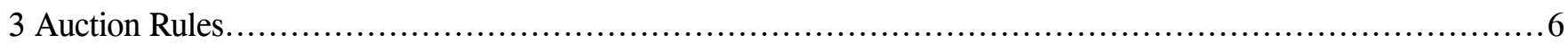

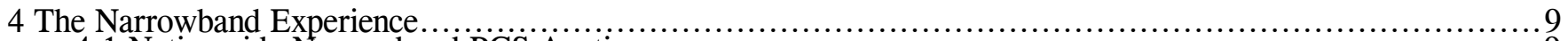

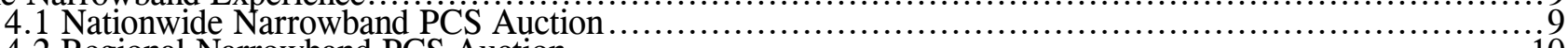

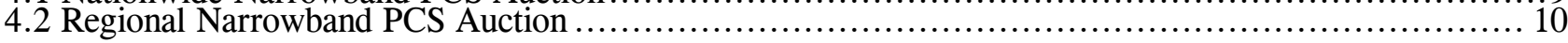

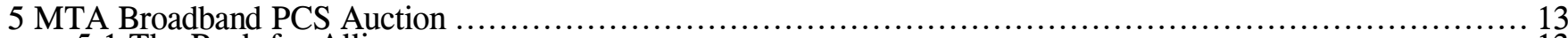

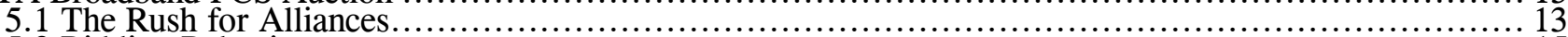

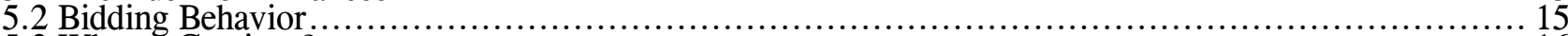

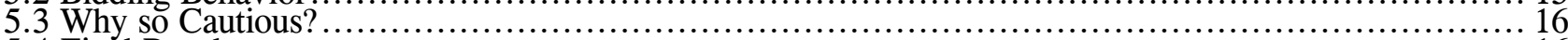

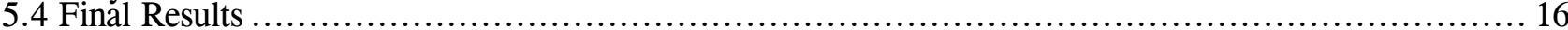

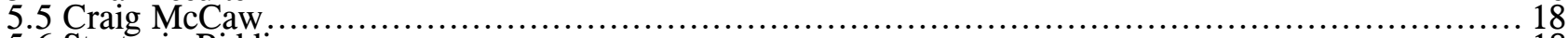

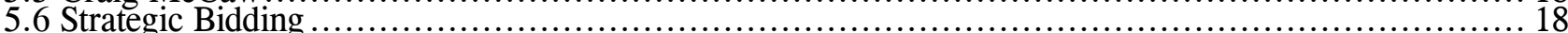

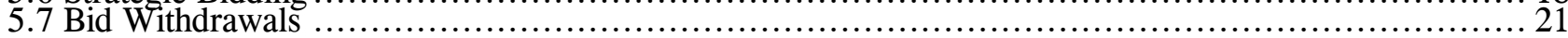

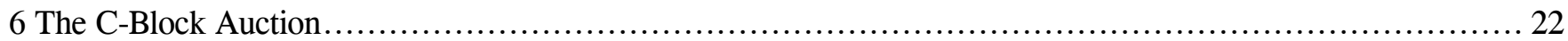

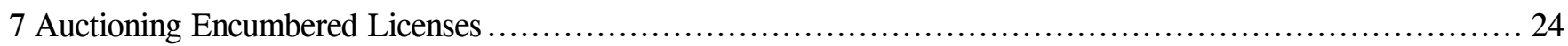

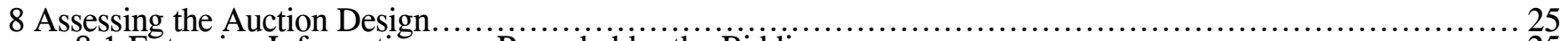

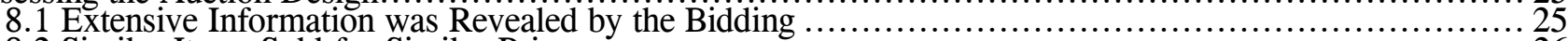

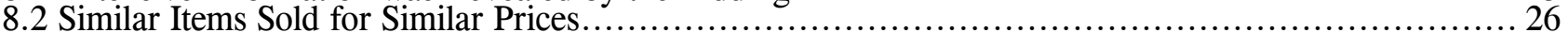

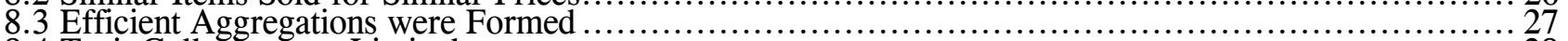

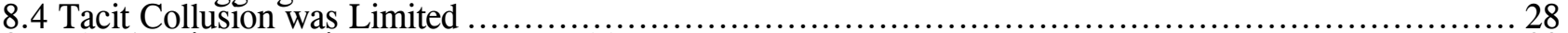

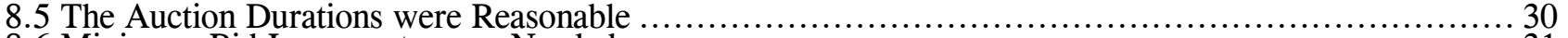

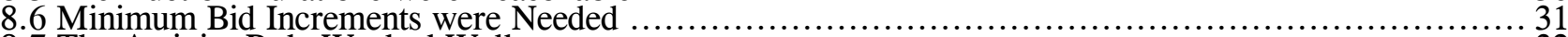

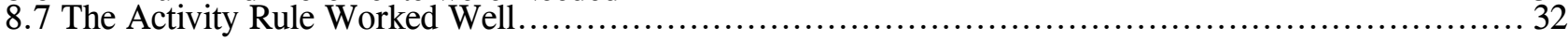

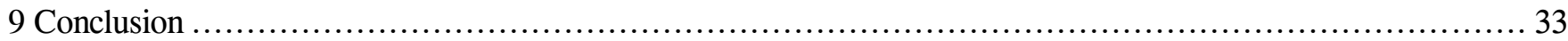

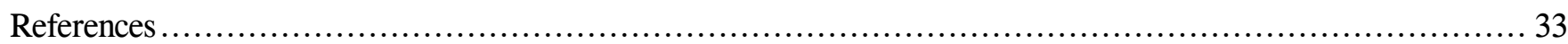




\section{Introduction}

The Federal Communications Commission (FCC) adopted a novel auction form to assign licenses for the next generation of wireless communication services. Up for auction were thousands of Personal Communication Services (PCS) licenses (and other licenses), each covering exclusive rights for a particular slice of the radio spectrum over a geographic area. These licenses, once developed by firms, promise to expand and improve wireless services and increase competition throughout telecommunications.

The licenses were assigned using a simultaneous multiple-round auction. This auction form was proposed by auction experts Paul Milgrom and Robert Wilson of Stanford University and Preston McAfee at the University of Texas. A simultaneous multiple-round auction is similar to a traditional ascending-bid "English" auction, except that, rather than selling each license in sequence, large sets of related licenses are auctioned simultaneously. In every round, a bidder can bid on any of the licenses being offered. The auction does not close until bidding has ceased on all licenses; that is, until a round goes by in which there are no new bids on any of the licenses.

There are three critical features of this method. First, the ascending-bid design allows the bidders to react to information revealed in prior rounds. This reduces the winner's curse, enabling the bidders to bid more aggressively (Milgrom and Weber 1982). Second, by auctioning a large set of related licenses simultaneously, bidders are able to react to prices across licenses. Since bidder valuations depend on the collection of licenses held, providing this price information on related licenses is essential to the formation of efficient aggregations of licenses. Some licenses are complements, whereas others are substitutes. The simultaneous sale of related licenses in an ascending bid auction, gives the bidders the flexibility they need to express these value interdependencies. In addition, it assures that similar licenses sell for similar prices. Third, keeping the bidding on all licenses open until there are no new bids gives the bidders flexibility in switching among license aggregations as prices change.

This paper looks at the first four PCS auctions and two auctions of other licenses to assess the auction's performance in practice. In evaluating the auction design, it should be recognized that efficiency was the primary goal of the FCC, not revenue maximization. The FCC sought to assign the licenses in a timely manner to those firms that will put the licenses to their best use. Fortunately for taxpayers, the goals of efficiency and revenue maximization often coincide. High prices are consistent with an efficient auction, since only bidders with high values are willing to pay high prices. This assumes that the high values are coming from a firm's advantage at providing better services at lower prices, rather than an advantage in restricting market competition. To reduce the chance that high values are derived from more collusive industry structures, the FCC limits the amount of spectrum a firm can hold in any market. Moreover, governments should care about the revenues raised at auction, since auction revenues are less distortionary than the principal source of government revenues - taxation. Ballard, et al. (1985) estimate that the welfare loss from increasing taxes is in the range of 17 to 56 cents per dollar of extra revenue raised. Hence, in designing the auction, the government should be willing to accept some assignment inefficiency if the gain in revenues is sufficiently large. ${ }^{1}$

I find strong evidence that the auction design was successful. The bidding process revealed a great

${ }^{1}$ See Ayres and Cramton (1996) for an analysis on the revenue enhancing effects of bidding credits and installment payments for small bidders in the Regional Narrowband auction. See Rothkopf and Harstad (1990) and Rothkopf, et al. (1996) for a more general analysis. 
deal of information about likely assignments and relative prices. Bidders were able to react to this information, shifting bids to alternative licenses. The information allowed arbitrage across similar licenses, so prices on similar licenses were close. Finally, the information revealed in the bidding enabled firms to piece together complementary licenses into efficient aggregations.

In order to test and refine the auction design, the FCC wisely chose to begin with the simplest of the auctions: the auction of ten nationwide narrowband PCS licenses. Narrowband licenses are used to provide advanced paging and data services. Because of the narrow bandwidth, they are ill-suited for commercial real-time voice services, like cellular. Cellular services require broadband licenses, which have up to 600 times the bandwidth $(30 \mathrm{MHz}$ vs. $50 \mathrm{kHz}$ ). Although the nationwide auction is the largest narrowband auction in terms of spectrum offered, it involves the smallest number of licenses and no geographic aggregation issues. However, a bidder can acquire up to three narrowband licenses in any area, so quantity aggregation is an issue. The nationwide auction lasted 47 rounds over five days in July 1994. In the end, the government collected $\$ 617$ million for the ten licenses. Competition was intense and bidding was aggressive throughout the auction. Cramton (1995) provides a detailed analysis of the nationwide auction from a bidder's perspective.

Next on the block were thirty regional narrowband licenses. Six licenses were sold in each of five regions. Thus, geographic aggregations would play a role, but would be much less complicated than in later auctions, which split the nation into smaller geographic areas, Major Trading Areas (MTAs) or Basic Trading Areas (BTAs). Despite a more rapid start, the auction, conducted in October and November 1994, took 105 rounds to complete. The government raised \$395 million. Most of the licenses were sold as nationwide aggregations. Prices were $12.4 \%$ higher than in the earlier nationwide auction. In addition, women and minorities won all ten licenses on which they were given a $40 \%$ bidding credit. However, competition among the women and minority bidders effectively eliminated the credit: prices were $40 \%$ higher on licenses receiving the credit than equivalent licenses without the credit.

These first two auctions were testing grounds for the third and most important spectrum auction, the MTA broadband PCS auction, which began on December 5, 1994 and ended March 13, 1995, after 112 rounds. This was the largest public auction ever. 99 MTA licenses were offered - two $30 \mathrm{MHz}$ licenses in each of 51 MTAs, with the exception of New York, Los Angeles, and Washington in which one of the two licenses in each market was awarded as a Pioneer's Preference (a reward to firms introducing pioneering technologies). Behavior in this auction differed markedly from the narrowband auctions. In particular, the bidding was much more cautious. Bids were mostly at or near the minimum level and a bidder's activity in any round was at or near the minimum activity required to maintain its eligibility. Nonetheless, the auction raised over $\$ 7$ billion ( $\$ 7.7$ billion including the Pioneer licenses).

In the second broadband auction, the third $30 \mathrm{MHz}$ of spectrum (the C-block) was auctioned as 493 BTA licenses. This auction was for small bidders only. Competition was intense and prices were high more than double those in the first auction. Attractive payment terms accounted for some of the difference, but differences in competition were also important. The auction raised $\$ 10.2$ billion in 184 rounds of bidding.

The final two auctions were for licenses that were heavily encumbered. The licenses up for sale were like Swiss cheese. Substantial holes existed where the FCC had previously awarded antenna-based licenses. The first was for Multipoint Distribution Services (MDS), commonly called "wireless cable," since the service is a wireless substitute for standard cable TV. The second, specialized mobile radio (SMR), is used for various wireless applications, such as taxi cab dispatching. Both auctions were competitive. Not surprisingly, incumbents where often successful in acquiring the residual areas of encumbered licenses and usually at a favorable price. 
I begin by outlining the design issues. Then I discuss the auction rules (section 3 ). In section 4 , I summarize the experience from the narrowband auctions. Sections 5 and 6 discuss bidding behavior in the MTA and BTA broadband auctions. Section 7 discusses the MDS and SMR auctions. Section 8 assesses the success of the auction design. The reader should be forewarned: this is a descriptive paper about the spectrum auctions. My claims are based only loosely on theory and empirical analysis. Much work remains to be done.

\section{Auction Design}

The design of the PCS spectrum auctions was the result of a rule making process carried out by the FCC from August 1993 to March 1994. Dozens of companies and their auction experts commented on the auction rules in an open public debate. Below I summarize several of the important issues. Although spectrum auction design is discussed elsewhere (McMillan 1994, Milgrom 1995, and Chakravorti et al., 1995), I review the issues here, since understanding the issues will be helpful in assessing the spectrum auctions.

\subsection{Open Bidding is Better than a Single Sealed Bid}

An essential advantage of open bidding is that the bidding process reveals information about valuations. This information promotes the efficient assignment of licenses, since bidders can condition their bids on more information. Moreover, to the extent that bidder values are affiliated, it raises auction revenues (Milgrom and Weber 1982), since the winner's curse is reduced. Bidders are able to bid more aggressively in an open auction, since they have better information about the item's value.

The advantage of a sealed-bid design is that it is less susceptible to collusion (Milgrom 1987). Open bidding allows bidders to signal through their bids and establish tacit agreements. With open bidding, these tacit agreements can be enforced, since a bidder can immediately punish another that has deviated from the collusive agreement. Signaling and punishments are not possible with a single sealed bid.

A second advantage of sealed bidding is that it may yield higher revenues when there are large ex ante differences among the bidders (Maskin and Riley 1995). This is especially the case if the bidders are risk averse (Maskin and Riley 1984, Matthews 1983). In a sealed bid auction, a strong bidder can guarantee victory only by placing a very high bid. In an open auction, the strong bidder never needs to bid higher than the second-highest value.

There was a consensus among experts (many of whom were employed by potential bidders) in favor of open bidding. The advantage of revealing more information in the bidding process was thought to outweigh any increased risk of collusion. Collusion was viewed as unlikely and revenue maximization was a secondary goal.

\subsection{Simultaneous Open Bidding is Better than Sequential Auctions}

A frequent source of debate was whether licenses should be sold in sequence or simultaneously. A disadvantage of sequential auctions is that they limit information available to bidders and limit how the bidders can respond to information. With sequential auctions, bidders must guess what prices will be in future auctions when determining bids in the current auction. Incorrect guesses may result in an inefficient assignment when license values are interdependent. A sequential auction also eliminates many strategies. A bidder cannot switch back to an earlier license if prices go too high in a later auction. Bidders are likely to regret having purchased early at high prices, or not having purchased early at low prices. The 
guesswork about future auction outcomes makes strategies in sequential auctions complex.

In a simultaneous auction, a large collection of related licenses is up for auction at the same time. Hence, the bidders get information about prices on all the licenses as the auction proceeds. Bidders can switch among licenses based on this information. Hence, there is less of a need to anticipate where prices are likely to go. Moreover, the auction generates market prices. Similar items sell for similar prices. Bidders do not regret having bought too early or too late.

The 1981 sale of rights to use an RCA communication satellite illustrates the practical importance of generating similar prices for similar licenses (McAfee and McMillan 1996). Seven identical licenses were sold in a sequence of ascending bid auctions. Prices ranged from $\$ 14.4$ million for the first license auctioned to $\$ 10.7$ million for the sixth. The bidder with the $\$ 14.4$ million winning bid petitioned the FCC to throw out the auction, because the auction procedure violated common carrier nondiscrimination rules. The FCC agreed and required RCA to charge the same price to all bidders.

Proponents of sequential auctions argue that the relevant information for the bidders is the final prices and assignments. They argue that simultaneous auctions do not reveal final outcomes until the auction is over. In contrast, the sequential auction gives final information about prices and assignments for all prior auctions. This final information may be more useful to bidders than the preliminary information revealed in a simultaneous auction.

Supporters of sequential auctions also point out that the great flexibility of a simultaneous auction makes it more susceptible to collusive strategies. Since nothing is assigned until the end in a simultaneous auction, bidders can punish aggressive bidding by raising the bids on those licenses desired by the aggressive bidder. In a sequential auction, collusion is more difficult. A bidder that is supposed to win a later license at a low price is vulnerable to competition from another that won an earlier license at a low price. The early winner no longer has an incentive to hold back in the later auctions.

A final advantage of a sequential auction is that it has been used extensively in practice and is easier to implement than a simultaneous auction. A sequence of oral auctions can be done quickly with little risk of failure. Adopting an unproven design, like the simultaneous auction, exposes the FCC to political embarrassment should the auction fail.

In the end, the advantages of simultaneous auctions won out. Decision makers at the FCC were convinced that the virtues of the simultaneous auction - greater information release and greater bidder flexibility in responding to information - would improve efficiency. Although the FCC was concerned that a simultaneous auction might be more collusive, it felt that the setting was otherwise not conducive to collusion. In any event, sequential auctions would not eliminate the possibility for collusion.

The ability to successfully implement a novel auction form was a chief concern. However, the FCC was able to test and refine the simultaneous auction in the simpler and lower stake setting of narrowband licenses. In addition, experimental tests of the design were conducted before the first narrowband auction began. Tests were conducted at CalTech's experimental lab by Charles Plott, David Porter, and John Ledyard. Several large bidders conducted their own tests as well. These tests provided evidence that the design would work in practice.

\subsection{Package Bids are too Complex}

A bidder's value of a license may depend on what other licenses it wins. Philadelphia may be worth more to a bidder if it wins the adjacent licenses in New York and Washington. Hence, bidders may value being able to bid on a combination of licenses, rather than having to place a number of individual bids. 
With a package bid, the bidder either gets the entire combination or nothing. There is no possibility that the bidder will end up winning just some of what it needs.

With individual bids, bidding for a synergistic combination is risky. The bidder may fail to acquire key pieces of the desired combination, but pay prices based on the synergistic gain. Alternatively, the bidder may be forced to bid beyond its valuation in order to secure the synergies and reduce its loss from being stuck with the dogs. This is the exposure problem. Individual bidding exposes bidders seeking synergistic combinations to aggregation risk.

Not allowing package bids can create inefficiencies. For example, suppose there are two bidders for two adjacent parking spaces. One bidder with a car and a trailer requires both spaces. She values the two spots together at $\$ 100$ and a single spot is worth nothing; the spots are perfect complements. The second bidder has a car, but no trailer. Either spot is worth $\$ 75$, as is the combination; the spots are perfect substitutes. Note that the efficient outcome is for the first bidder to get both spots for a social gain of $\$ 100$, rather than $\$ 75$ if the second bidder gets a spot. Yet any attempt by the first bidder to win the spaces is foolhardy. The first bidder would have to pay at least $\$ 150$ for the spaces, since the second bidder will bid up to $\$ 75$ for either one. Alternatively, if the first bidder drops out early, she will "win" one license, losing an amount equal to her highest bid. The only equilibrium is for the second bidder to win a single spot by placing the minimum bid. The outcome is inefficient, and fails to generate revenue. In contrast if package bids are allowed, then the outcome is efficient. The first bidder wins both licenses with a bid of $\$ 75$ for both spots.

The inefficiency in this example does not rely on there being full information about values. If values are privately known, then the first bidder will decide to bid for the pair only if it is sufficiently likely that the second bidder has a low value. Otherwise the exposure is too great and the first bidder will not participate.

This example is extreme to illustrate the exposure problem. The inefficiency involves large bidderspecific complementarities and a lack of competition. In the PCS auctions, the complementarities are less extreme and the competition is greater.

Unfortunately, allowing package bids creates other problems. Package bids may favor bidders seeking large aggregations due to a variant of the free-rider problem, called the threshold problem (Bykowsky, et al. 1995). Continuing with the last example, suppose that there is a third bidder who values either spot at $\$ 40$. Then the efficient outcome is for the individual bidders to win both spots for a social gain of $75+40=\$ 115$. But this outcome may not occur when values are privately known. Suppose that the second and third bidders have placed individual bids of $\$ 35$ on the two licenses, but these bids are topped by a package bid of $\$ 90$ from the first bidder. Each bidder hopes that the other will bid higher to top the package bid. The second bidder has an incentive to understate his willingness to push the bidding higher. He may refrain from bidding, counting on the third bidder to break the threshold of $\$ 90$. Since the third bidder cannot come through, the auction ends with the first bidder winning both spaces for $\$ 90$.

A second problem with allowing package bids is complexity. If all combinations are allowed, even identifying the revenue maximizing assignment is an intractable integer programming problem when there are many bidders and licenses. The problem can be made tractable by restricting the set of allowable combinations (Rothkopf, et al. 1995). However, these restrictions may eliminate many desirable combinations, especially in broadband PCS where cellular holdings and other existing infrastructure tend to create idiosyncratic license synergies. Alternatively, a bid mechanism can be used that puts the computational burden on the bidders. In the AUSM system, bidders must propose bids that in combination with other bids exceed the amount bid for standing package bids (Banks, et al. 1989). 
Increased complexity is a legitimate concern when considering package bids. Although simultaneous auctions with package bids were successfully used in the laboratory (Bykowsky, et al. 1995), it was far from certain that the FCC could successfully run auctions with package bids under the tight time schedule. Furthermore, allowing package bids would weaken a central advantage of auctions: transparency. A bidder who offered a higher bid for part of a combination might be unable to see why it lost.

The FCC decided against allowing package bids. The threshold problem and increased complexity of package bids were thought to be worse than the exposure problem.

\subsection{Other Issues}

Having settled on a simultaneous ascending-bid auction without package bids, several issues of implementation remained.

How much information should the bidders be given? The insights from Milgrom and Weber (1982) suggest that typically more public information is better. Hence, with the exception of bidder identities in the nationwide auction, the FCC decided to reveal all information: the identities of the bidders, all the bids, and the bidders' current eligibility. So long as collusion and predatory bidding are not problems, revealing more information should improve efficiency and increase revenues. It also makes for a more open process.

Should the rounds be discrete or continuous? The FCC decided on discrete rounds, which would give the bidders a specific amount of time to respond to bids. Continuous bidding has the advantage that it makes endogenous the time between bids. Bidders can respond quickly when the strategic situation is simple, and take more time when it is complex. Discrete bidding is easier to implement and it gives the bidders a specific schedule to follow. Bidders know exactly when new information will be available and when they have to respond.

How can the FCC best control the pace of the auction? There are three key instruments: the frequency of rounds, the minimum bid increments, and an activity rule, which sets minimum levels of bidding activity. These are discussed later.

\section{Auction Rules}

The basic rules for the auctions are the same. A group of licenses with strong value interdependencies are up for auction at one time. A bidder can bid on any collection of licenses in any round, subject to an activity rule which determines the bidder's current eligibility. The auction ends when a round passes with no new bids on any license. This auction form was thought to give the bidders the greatest flexibility in expressing values and building license aggregations. An auction winner gains the exclusive right to use the spectrum in accordance with FCC rules for a period of ten years. Licenses typically are renewed with a negligible charge provided the licensee has adhered to FCC rules and met buildout requirements. Licensees at any time may resell licenses purchased without special preference. Resale of licenses purchased with special preference is restricted to prevent "unjust enrichment."

Within this basic structure, some of the details differ among the auctions. Here I mostly focus on the MTA broadband rules. Detailed auction rules for the narrowband auctions are given in the FCC's Third Report and Order (1994); the rules for the broadband auctions are given in the Fifth Report and Order (1994). Refinements were made in subsequent public notices and orders on reconsideration.

Quantity Restrictions. To promote competition, a firm is limited in the quantity of spectrum it can 
hold in any market. For narrowband spectrum, a firm can hold no more than three licenses in any market. For broadband auctions, firms can hold no more than $45 \mathrm{MHz}$ of commercial mobile radio service (CMRS) spectrum in any area. PCS and cellular are classified as CMRS spectrum. Hence, a cellular incumbent (a $25 \mathrm{MHz}$ license) is ineligible to bid for a $30 \mathrm{MHz}$ license in its service area. This assures that each $30 \mathrm{MHz}$ license in every market will be held by distinct firms, independent of the two cellular incumbents.

Designated Entities. To encourage broad participation in wireless communications, designated firms (women, minorities, and/or small businesses) were given bidding credits on specific licenses. These credits, ranging from $10 \%$ to $40 \%$, were intended to offset any disadvantage these firms faced in raising capital and providing services. Designated firms often were eligible for attractive installment payment plans also. No preferences were given in the MTA broadband auction. However, in the C-block auction, only entrepreneurs (annual revenues less than \$125 million) and small businesses (annual revenues less than $\$ 40$ million) were eligible to bid.

Payment Rules. Payments are received by the FCC at three times: (1) An upfront payment before the bidding begins assures that the bidder is serious. Any withdrawal penalties are taken from the bidder's upfront payment. ${ }^{2}$ (2) A down payment of 20 percent is paid within five business days after the close of the auction. (3) A final payment of the remaining 80 percent is paid within five business days of the award of the license. Firms eligible for installment payments have a reduced down payment and make quarterly payments over 10 years. Licenses are awarded one to three months after the auction.

The upfront payment, due two weeks before the auction begins, defines the bidder's maximum eligibility in any round of bidding. Each bidder must make an upfront payment of $\$ .02$ per MHz-pop for the largest combination of licenses the bidder intends to be active on in any round. The size of a PCS license is measured in MHz-pop: the bandwidth in megahertz times the population in the license area. A bidder is active on a license if it places a valid bid or was the high bidder on the license in the prior round. Thus, an upfront payment of $\$ 6$ million in the broadband auction would make a bidder eligible to be active on licenses covering $6 /(30 \cdot .02)=10$ million people. The upfront payment is not license specific; it simply limits total bidding activity in any round.

Minimum Bid Increments. To assure that the auction concludes in a reasonable amount of time, the FCC specifies minimum bid increments between rounds. Initially, bid increments are set at the greater of $5 \%$ or $\$ .02 / \mathrm{MHz}$-pop. Before a license receives a bid, the minimum bid is 0 . Bid increments are adjusted in response to bidder behavior. In the early rounds, when bid activity is high, the FCC sets larger bid increments; in the later rounds, when bid activity is low, the FCC sets smaller bid increments.

Activity Rule. The activity rule is a further device for controlling the pace of the auction. It forces a bidder to maintain a minimum level of activity to preserve its current eligibility. As the auction progresses, the required activity increases in stages. There are three stages in the activity rule proposed by Paul Milgrom and Robert Wilson. In the initial stage each bidder must be active on at least one-third of its current eligibility. Activity is measured as the sum of the MHz-pops on which the bidder submitted a valid

\footnotetext{
${ }^{2}$ The importance of significant upfront payments is illustrated by the Interactive Video Data Services (IVDS) auction, held on July 27-28, 1994. This auction was marred by several defaults. Upfront payments were only $\$ 500$ per license for licenses valued in excess of one million dollars. Defaults occurred on 114 of 574 licenses. The defaults came from a handful of speculators that apparently did not understanding the rules or the technology before the auction. A large upfront payment, which serves as a deposit to ensure payment of a penalty in the event of default, provides an incentive for bidders to be well-prepared.
} 
bid or was the high bidder. If activity falls below the one-third level, then the bidder's current eligibility is reduced to three times its current activity. In stage 2, a bidder must be active on at least two-thirds of its current eligibility. If its activity falls below the two-third level, the bidder's current eligibility is reduced to 1.5 times its current activity. In stage 3 of the auction, a bidder must be active on 100 percent of its current eligibility. If its activity falls below 100 percent, the bidder's current eligibility is reduced to its current activity.

A waiver prevents a reduction in eligibility in the event of bidder error or some other problem. Bidders are given five waivers. (In the regional auction each bidder was given one waiver per stage.) Waivers are applied automatically. An automatic waiver is used whenever a bidder's eligibility would otherwise fall as a result of its reduced bid activity. A bidder that does not wish to maintain its eligibility from the prior round may override the automatic waiver.

Number of Rounds per Day. A final means of controlling the pace of the auction is the number of rounds per day. In the narrowband auctions, many rounds were conducted each day. This made sense given the relatively small number of licenses and more modest stakes. The time between rounds was longer early in the auction (about 2 hours), but shortened toward the end when bidding activity was low and strategies were simple. At the end of the nationwide auction, rounds were occurring every 20 minutes. In the MTA auction, the number of rounds per day was much less. Initially only one round was conducted per day. After the first week, typically two rounds were conducted each day.

Stopping Rule. A simultaneous stopping rule is used to give the bidders maximum flexibility in pursuing backup strategies. All markets close if a single round passes in which no new bids are submitted on any license. In the MTA auction, the FCC retained the right to keep the auction open if there were no new bids in a round. This prevents a premature close of the auction at the end of stages 1 and 2 if bidders simply are bidding to maintain eligibility. It also allows the FCC to use a larger bid increment. If the increment chokes off activity, then the FCC can drop the increment and/or move to the next stage in order to restore bid activity.

Bid Information. ${ }^{3}$ Each bidder is fully informed about the identities of the bidders, the size of the upfront payments, and which bidders qualify as designated entities. High bids and bidder identities are posted after each round. In addition, all valid bids and bidder identities are displayed at the conclusion of each round, together with each bidder's eligibility and waivers. ${ }^{4}$

Bid Withdrawal. After the close of each round, there is a brief withdrawal period in which the high bidders can withdraw their bids subject to a bid withdrawal penalty. If a bidder withdraws its high bid, the FCC is listed as the high bidder and the minimum bid is the second-highest bid for that license. The second-highest bidder is in no way responsible for the bid. If no firm bids on the license, the FCC can reduce the minimum bid. Typically, the FCC drops the minimum bid only one or two times, before committing not to reduce the minimum bid further. A withdrawn high bid counts as bidding activity for

\footnotetext{
${ }^{3}$ Readers can obtain the bidding data for all of the auctions by anonymous $\mathrm{ftp}$ at $\mathrm{ftp}$.fcc.gov. For the last four auctions, tracking tools created by the author are also available. These tools enable the user to analyze the bidding data within a spreadsheet environment. See the FCC's Web site at www.fcc.gov.

${ }^{4}$ In the nationwide auction, bidder identities were not disclosed. It was thought that concealing identities might reduce the chance of predatory bidding (bidding to raise rivals' costs) and collusion. However, concealing identities was largely unsuccessful, and predatory bidding and collusion were not problems (Cramton 1995); hence, the decision to reveal identities in subsequent auctions.
} 
the high bidder in the round the bid is withdrawn. This enables the bidder to switch licenses without losing eligibility.

To discourage insincere bidding, there are penalties for withdrawing a high bid. The penalty is the larger of 0 and the difference between the withdrawn bid and the final sale price. This penalty is consistent with the standard remedy for breach of contract. The penalty equals the damage suffered by the FCC as a result of the withdrawal. If the bidder defaults or is disqualified after the close of the auction, the penalty is increased by $3 \%$ of the eventual sale price to compensate the FCC for additional selling costs. The additional 3\% default payment is also intended to discourage defaults (after the auction closes) relative to withdrawals (during an auction).

\section{The Narrowband Experience}

The nationwide and regional narrowband auctions served two important roles. First, the auctions assigned narrowband spectrum, allowing winning firms to begin offering advanced paging services. Second, they provided an opportunity to test and refine the rules for the all important MTA broadband auction. In this section, I summarize the bidding behavior in the narrowband auctions and its implication for the broadband auction.

\subsection{Nationwide Narrowband PCS Auction}

Up for auction were ten nationwide licenses in three different types: 50/50 kHz paired licenses $(50 / 50 \mathrm{~s}), 50 / 12.5 \mathrm{kHz}$ paired licenses $(50 / 12 \mathrm{~s})$, and $50 \mathrm{kHz}$ unpaired licenses (50s). With the "paired" licenses, the first number denotes the amount of outbound capacity (from network to consumer) and the second number denotes the amount of inbound capacity (from consumer to network). An unpaired license consists of only outbound capacity. Inbound bands are not the same as outbound bands, because of differing power constraints. Hence, one $50 / 50 \mathrm{kHz}$ paired license is not the same as two $50 \mathrm{kHz}$ unpaired licenses. There are five 50/50s (blocks 1 to 5), three 50/12s (blocks 6 to 8), and three 50s (blocks 9 to 11). License 9 was not up for auction because it had been set aside for Mtel as a Pioneer's Preference award. Women and minorities were given a $25 \%$ bidding credit on one license of each type (blocks 5, 8, and 11).

The auction began July 25, 1994 and concluded July 29, after 47 rounds. Of the 29 bidders that submitted upfront payments, four bidders failed to show up at the auction. Eight more bidders dropped out in the first round, leaving 17 bidders competing for the 10 licenses. In the end, licenses were won by six firms, as shown in Table 1. Price is stated in \$/MHz-pop (i.e., the cost of the license in dollars divided by the product of the size of the license in megahertz and the population covered, which is 253 million for a nationwide license). This makes prices among license types comparable. One remarkable aspect of the outcome is that the final prices for all the licenses were nearly equal at about $\$ 3.10$ per MHz-pop. Within a license type, prices were nearly identical.

Bidders were able to form efficient aggregations. Those winning multiple licenses (PageNet and McCaw) acquired adjacent bands. Owning adjacent bands increases the firm's capacity, since it can use the guard band, which separates adjacent bands, for transmission. Otherwise, the guard band must be clear to prevent interference between adjacent bands.

Figure 1 displays the auction revenue and a measure of bid activity (the percent of new bids) in each round. Revenues increased rapidly early in the auction when bid activity was high. As prices increased, bid activity declined as did the rate of increase in revenues. Bidding was aggressive throughout the auction. Indeed, minimum bid increments proved unimportant. Bidders routinely bid well in excess of the 
minimum. The activity rule also played no role. The auction never left stage 1 . The FCC felt the auction was progressing sufficiently quickly, so that stage 2 was not needed.

None of the three licenses with the designated entity (DE) bidding credit were won by designated entities. A $25 \%$ bidding credit was insufficient to attract sufficient DE capital to win a license. One explanation is that the designated entities were surprised by and unprepared for the high prices. Indeed, most of the DEs dropped out in the first round of the auction.

There was a tendency for the bidding to move down from the larger licenses (50/50s and 50/12s) and then to the smaller licenses (50s). Through the first 18 rounds, bidding was primarily on the 50/50s and $50 / 12 \mathrm{~s}$. After round 19, bidding stopped for 7 rounds on the 50/50s, but then resumed again in round 26, before concluding in round 37. Bidding on the 50/12s was heavy throughout the first half of the auction, but concluded in round 25, 21 rounds before the end of the auction. Bidding on the 50s was light and steady throughout the auction. The last 9 rounds of the auction involved new bids on only the 50s. In the final eight rounds, there was just a single new bid in each round - three bidders were competing for two licenses.

Jump bidding - the act of raising a high bid by much more than the minimum increment - was pervasive throughout the auction. $49 \%$ of all new high bids were jump bids that exceeded the high bid by more than two bid increments. 23\% of these jump bids were raises of one's own high bid (bidders anticipating a raise by a rival). Even in the opening round, with minimum bids between $\$ 250,000$ and $\$ 500,000$, bidding started at $\$ 20$ million on two licenses and $\$ 10$ million on five others. The $\$ 20$ million opening exceeded the minimum bid by a factor of 40 . This behavior seems to fly in the face of common bidding wisdom. However, there may be good reasons for jump bidding, especially in an auction where the aggregation of licenses plays a role. The basic idea is that the jump bid may convey information about a bidder's valuations. It is a message of strength, conveying that the bidder has a high value for the particular license. Jump bidding has a cost - it exposes the bidder to the possibility of leaving money on the table. It is precisely this cost that makes the communication credible. A bidder with a low value would not find it in its interest to make a large jump. The gain, increasing the chance of winning the license, would not exceed the cost, the risk of overbidding. It is not enough for a bidder to simply announce, "I have a high value. You had better look elsewhere." All bidders, high value and low value alike, have an interest in making such a statement. To make the statement credible the words must be backed up by an action that a low value bidder would find too costly.

Signaling a high value is a good thing for a bidder to the extent it gets rivals to look elsewhere. This may be the case if there are strong synergies among licenses. A bidder's confidence about the chance it can form a desirable aggregation should fall if it is convinced a rival has a high value. However, the cost of staying in may be zero for a bidder looking for a single license. For the most part, jump bidding appeared not to discourage firms from bidding. Avery (1994) provides an equilibrium analysis of jump bidding in a common value setting.

The simultaneous multiple-round auction was remarkably successful in this first PCS auction. Competition was intense, similar items sold for similar prices, and aggregations appeared efficient. Interestingly, the bid increments and activity rules proved unimportant. Firms bid aggressively and were rarely constrained by bid increments or activity rules.

\subsection{Regional Narrowband PCS Auction}

This auction was of special interest, because it used rules that were nearly identical to the rules in the MTA broadband PCS auction. Although these rules were used in the nationwide auction, the nationwide 
auction did not allow the possibility for forming geographic aggregations. In the regional auction, the formation of geographic license aggregations was critical. Hence, the regional auction gave us a first glimpse of bidding behavior designed to form large geographic aggregations. ${ }^{5}$

The regional narrowband PCS auction began on October 26, 1994, and ended on November 8, after 105 rounds. Initially, there were 28 bidders competing for the 30 regional licenses. Six bands (two 50/50s and four 50/12s) were offered in each of five regions. In the end, nine firms won licenses. Table 2 indicates the final outcome. Prices ended $12.4 \%$ above the prices in the nationwide auction. Most of these regional licenses went to firms with a nationwide strategy (PageMart, PCS Development, Mobile Media, Advanced Wireless, and AirTouch). Figure 2 tracks the progress of the auction round by round. After the first six rounds, it was a much slower auction than the nationwide auction.

The first round of the auction set the stage for an early escalation in prices. PCS Development opened with bids totalling $\$ 80$ million (\$48 million net of the DE credit) for a nationwide aggregation of 50/50s, matching the final price from the nationwide auction. Clearly the information revealed in the nationwide auction played a role in the regional auction. PageMart opened with two nationwide bids of $\$ 32$ million on the 50/50s, as well as two nationwide bids on the 50/12s. Mobile Media opened with three nationwide bids of $\$ 20$ million each on a 50/50 and two 50/12s. Most of the other bidders were more cautious. Forming a nationwide aggregation clearly was important for several bidders.

By round 7, the assignment of licenses was quite close to the final assignment reached nearly 100 rounds later. PageMart, PCS Development, Mobile Media, and Advanced Wireless each had staked out a nationwide aggregation on blocks 1 to 4, respectively. AirTouch apparently wanted licenses in three regions. The biggest disagreement was on the 50/12 DE block. Both Shearing and Benbow were fighting for a nationwide aggregation. Prices increased by about $40 \%$ over the final 96 rounds on bidding activity sparked by the excess demand of DE bidders. As in the nationwide auction, predictions of a rapid end of the regional auction proved false. The long end is partly explained by the greater number of licenses and substitution possibilities, and partly by the use of a $2 \%$ bid increment after round 20 , rather than $5 \%$. However, since many rounds were conducted each day, the use of this smaller increment extended the auction less than one week.

Unlike in the nationwide auction, the regional auction involved three stages of bidding. Stage 2 began in round 21 (a bidder must be active on two-thirds of its current eligibility). Since most bidders were bidding aggressively in stage 1 , the move to stage 2 had little effect. There was a modest increase in activity for a few rounds. Stage 3 began in round 74 (a bidder must be active on $90 \%$ of its current eligibility). Bidding activity picked up slightly. Mostly this was caused by 50/12 bidders keeping the 50/50 option open by bidding on two 50/12s, rather than one.

Also unlike in the nationwide auction, bid withdrawals were observed in the regional auction. In round 78, PCS Development withdrew its bid of $\$ 18$ million on block 6 in the Western region. The final selling price was $\$ 18.2$ million, so no penalty was incurred. The withdrawal was the result of strategic bidding, not a shift in license aggregations. PCS Development's bid on block 6 was an attempt to punish Shearing for repeated bidding on block 2, which PCS Development wanted as a nationwide aggregation. The only other withdrawal occurred in round 83 when PageMart withdraw its bid of $\$ 10.129$ million on block 5 in the Southern region and shifted to blocks 3 and 4. The final selling price was $\$ 8$ million, so PageMart incurred a withdrawal penalty of $\$ 2.129$ million. This withdrawal also was due to strategic bidding. PageMart needed to bid on two 50/12s to maintain eligibility so that it could return to the 50/50

\footnotetext{
${ }^{5}$ See Ayres and Cramton (1996) and Milgrom (1995) for analysis of the regional auction.
} 
license in block 2 if prices on the 50/12s increased too much. Apparently PageMart reasoned that it was better to bid against the nationwide aggregations of Mobile Media (block 3) and Advanced Wireless (block 4). Winning these licenses would mean success in breaking up two nationwide competitors. At worst, the bids would raise the costs of PageMart's nationwide competitors and enable a move up to the 50/50. Perhaps PageMart thought that someone might be willing to pick up the 50/12 on block 5 at the withdrawal price. However, it was too late in the auction. The block $550 / 12$ was not picked up until the FCC dropped the minimum price to $\$ 8$ million (from $\$ 9.93$ million). At this price InstaCheck was willing to move off the Northeast license, ending the auction.

A remarkable feature of the regional auction was the role designated entity bidders played in determining prices. All DE licenses were sold to DEs. Of the 28 bidders, 20 had some kind of DE preference. Nearly one-half of the upfront payments came from DE bidders. Competition among the DEs was so intense that the $40 \%$ bidding credit was entirely bid away. DE bidders paid roughly the same net prices as non-DE bidders. The effective DE discount on block 2 was $1.8 \%$ and the discount on block 6 was $-2.2 \%$.

This was in stark contrast to the outcome in the nationwide auction in which the DEs dropped out early, most after the first round of bidding. The difference in outcome was largely due to changes in the DE rules. Although the increase in the bidding credit from $25 \%$ to $40 \%$ was the most obvious change, it probably was unimportant. Either credit would have kept non-DE bidders out of the DE licenses. Hence, it was competition among DEs that determined prices on the DE licenses, rather than competition between DE and non-DE bidders. Two other changes were critical. First, allowing installment payments for DE bidders at attractive terms (10-year Treasury rate) solved one of the major problems DEs face - the raising of capital. Second, the definition of women and minority controlled firms was relaxed. In the nationwide auction, $50.1 \%$ equity ownership by women/minorities was required. In the regional auction, $25 \%$ equity ownership was sufficient as long as the women/minorities had voting control and no other investor owned more than $25 \%$. This made it easier for DE firms to partner with existing paging companies, which solves the second major problem facing DE bidders: acquisition of technical knowledge. Each of the bidders winning DE licenses partnered with one or more established paging companies. PCS Development partnered with A-Plus, Arch, and USA Mobile; Benbow partnered with Westlink; and Shearing partnered with Adelphia. These partnerships brought essential knowledge in addition to capital to the DE firms. As a result, these DE bidders did not look much different from the non-DEs. A third important factor in the success of the DEs was that much of the uncertainty about prices was resolved in the nationwide auction. DE bidders had the time and the knowledge to adequately prepare for the regional auction.

One of the puzzles in the regional auction was that prices were $12.4 \%$ higher than in the nationwide auction. Evidence from wine auctions suggests that, when similar items are sold in sequence, the later items tend to sell for less than the early items. This is known as the "declining price anomaly" (Ashenfelter 1989, McAfee and Vincent 1993). ${ }^{6}$ One explanation for the rise in prices is the more favorable DE rules. These rules, which were not known at the time of the nationwide auction, brought more capital to the auction and effectively reduced the supply of non-DE licenses. This reduction in supply raised prices for the non-DE bidders. Moreover, competition among DE bidders was so strong that the DE bidders crossed over to the non-DE licenses, raising the revenues from non-DE licenses by more than $\$ 50$

${ }^{6}$ There are exceptions to declining prices. Gandal (1995) finds that prices tended to increase in the sequential sale of Israeli cable television licenses. Apparently firms were willing to pay more for later licenses, because of complementarities. 
million (Ayres and Cramton 1996). The favorable treatment of DE bidders had the effect of increasing auction revenues. Such a conclusion is consistent with auction theory. When bidders are asymmetric ex ante, the revenue maximizing auction will tend to favor the weak bidders (Myerson 1981, McAfee and McMillan 1987). By favoring the weaker party, the weaker party can compete more effectively with the strong firms. This heightened competition tends to raise prices.

An alternative explanation for the higher prices in the regional auction is that competition was greater because of the presence of several bidders with regional strategies. However, since most regional licenses were sold as nationwide aggregations, many of the winning firms in the regional auction could have purchased in the nationwide auction, reducing prices in the regional auction.

Another explanation for the higher prices in the regional auction is that, because of the obvious interest in single-band nationwide aggregations, firms were able to impose costs on competitors by bidding on a piece of a competitor's nationwide aggregation. There is some evidence of such predatory bidding.

The regional auction made clear that it is possible for firms to form large aggregations in a simultaneous multiple-round auction. Moreover, it showed that the nationwide prices were no fluke and that DE preferences could have pronounced effects on competition and outcomes. Although the activity rule continued to be of little importance in this auction, low bid increments did lengthen the end of the auction.

\section{MTA Broadband PCS Auction}

On December 5, 1994, the first and most important broadband PCS auction began. One-half of the $120 \mathrm{MHz}$ of broadband spectrum was on the block: two $30 \mathrm{MHz}$ licenses (bands A and B) in each of 51 MTAs, less the three Pioneer's Preference awards (the A license in New York, Los Angeles, and Washington). The 51 MTAs range in size from New York with 26.4 million people to American Samoa with 47 thousand people. The ten largest MTAs cover $50 \%$ of the population. The two narrowband auctions, allocating just $1.2 \mathrm{MHz}$ of spectrum, were small compared to the $60 \mathrm{MHz}$ allocated in the MTA broadband auction. Competing in the auction were some of the largest telecommunication companies in the world, as well as many smaller firms. There were no benefits to designated entities. Benefits to DEs would come in later auctions when the remaining $60 \mathrm{MHz}$ of spectrum is sold. The auction ended on March 13, 1995 after 112 rounds and three months of bidding. The government collected over $\$ 7$ billion (\$7.7 billion including the Pioneer payments). ${ }^{7}$

\subsection{The Rush for Alliances}

To be eligible to bid, a bidder had to submit a Short Form Application by October 28, 1994. The Short Form specified all alliances and listed the licenses on which the firm wished to bid. All partnering had to occur by October 28. The FCC allowed alliances, because they might be essential to efficiency. For example, a nationwide service might be efficient, due to marketing advantages, but no individual firm may have the resources to bid for one. On the other hand, alliances may reduce efficiency by limiting competition in the auction. During the two weeks before the deadline, there was a frenzy of activity in

\footnotetext{
${ }^{7}$ The Pioneer's Preference winners pay for their licenses according to a formula in the GATT legislation. Each pays the greater of $\$ 7.50$ /pop or $85 \%$ of the unweighted per pop price in the top-23 markets excluding New York, Los Angeles, and Washington. The formula was included as an amendment to GATT to make the legislation revenue neutral.
} 
forming alliances. The largest telecommunication companies in the world were engaged in a last-minute dance to form alliances that would shape the future of PCS and have far reaching implications throughout telecommunications. ${ }^{8}$

In the end, two large alliances formed: WirelessCo, a limited partnership between Sprint (40\%) and three large cable companies: TCI (30\%), Comcast (15\%), and Cox (15\%); and PCS PrimeCo, a collection of three Bell Operating Companies (BOCs) (Bell Atlantic, Nynex, and USWest) and AirTouch, the wireless spinoff of PacTel. The four companies in PrimeCo first got together as pairs: USWest-AirTouch and Bell Atlantic-Nynex. Each firm has a $25 \%$ stake in PrimeCo. The alliance was in part prompted by a desire by the Bell Atlantic-Nynex pair to secure Los Angeles. There appeared to be a consensus in the industry that PacTel would win the only available license in Los Angeles. Cox held the other as a Pioneer's Preference award, and was already aligned with WirelessCo. Hence, Bell Atlantic-Nynex apparently felt that their best way to get coverage in Los Angeles was to partner with either PacTel or USWest-AirTouch. AirTouch held one of the two cellular licenses in Los Angeles.

These alliances were significant because they greatly reduced eligibility. Since bidders could not bid in any market in which they hold a significant cellular interest, joining forces with a large cellular provider reduced eligibility. Firms had a double incentive to join. First, merger would enable the firms to serve a larger geographic area, perhaps near-nationwide, which has many advantages for marketing. Consumers value seamless roaming and national advertising campaigns then can be used. Second, merger reduces the number of bidders and the bidders' eligibility. Any merger that includes the marginal bidder (the bidder with the third-highest value) reduces the price paid.

The WirelessCo merger likely increased competition by combining complementary assets: long distance, national marketing, and local cable networks. Neither Sprint, nor the cable companies, were well positioned to go it alone, but together they represented a strong force. Moreover, since none of the firms had sizeable cellular holdings, the alliance made WirelessCo ineligible to bid on only $17 \%$ of the population.

In contrast, the PrimeCo alliance reduced competition in the auction. The BOCs and AirTouch all had sufficient capital to form substantial aggregations independently. By joining forces, the number of deeppocketed bidders was reduced as was total eligibility. PrimeCo was excluded from bidding on $64 \%$ of the population as a result of the cellular holdings of its members. Hence, the alliance eliminated three deeppocketed bidders in nearly two-thirds of the U.S. and turned four bidders into one in the remaining third.

Finally, AT\&T's acquisition of McCaw Cellular for $\$ 11.5$ billion meant that AT\&T would be ineligible to bid on licenses covering $48 \%$ of the population.

Although 62 bidders submitted short form applications for the auction, only 30 followed through with upfront payments. The upfront payments totalled $\$ 522$ million. The largest (\$118 million for 197 million pops of eligibility) was from WirelessCo. Four firms put up the minimum upfront payment of \$28 thousand, enough to bid on American Samoa.

One consequence of the two major alliances was a reduction in total eligibility. This auction began with an eligibility ratio (total eligibility in pops divided by total pops being auctioned) of 1.93 . The

\footnotetext{
${ }^{8}$ Bidders were allowed to form alliances during the auction, but only with bidders applying for a disjoint set of licenses. This option was not used by any of the bidders. It only works with bidders with very focused interests - those applying for only a few licenses. But bidders with focused interests have little to gain by forming alliances with bidders outside their interests.
} 
eligibility ratios in the narrowband auctions were several times this amount. The eligibility ratio in the nationwide auction was 8.8 and was 6.1 in the regional auction. Some potential bidders with limited capital probably were scared off by the thought of bidding against the likes of AT\&T and PrimeCo. At least one bidder, Craig McCaw, bidding as Alaacr Communications, recognized that prices might be low in some markets. McCaw reasoned that there were few large bidders and in many markets two or more of the largest firms were excluded from bidding because of cellular ownerships. Hence, McCaw decided at the last moment to participate. In deference to his former employees at McCaw Cellular (now part of AT\&T), McCaw applied for every license that AT\&T did not apply for.

Three of the firms, WirelessCo, AT\&T, and PrimeCo, went into the auction with a nationwide strategy. Each firm wanted to fill the holes in its cellular network. Other firms had focused geographic interests. PacTel, for example, announced its intent to win Los Angeles and San Francisco, although it applied for all licenses. Ameritech was only interested in two midwest licenses. GTE was interested in a handful of licenses that would work well with its existing network. Several firms applied for just a single license, making a clear statement about their intent. In contrast, McCaw was looking for value wherever it might be.

One of the major differences between this auction and the narrowband auctions was the extent of ex ante asymmetries among the firms. Values in broadband PCS are closely related to the network infrastructure the firm already has in place. This geographic heterogeneity together with the much smaller geographic markets means that in many instances the firms have a good idea who the high valuers are likely to be in many markets. PacTel has high values in Los Angeles and San Francisco; Ameritech has high values in Cleveland and Indianapolis; AT\&T has high values in Washington and Chicago; PrimeCo has high values in Chicago and Dallas. If the known differences are large, it is possible that at least in some markets, the assignment will be resolved without using price to drive away bidders with lower values. If all the bidders know that PacTel has the highest value in Los Angeles, there is less incentive for a bidder to bid against PacTel in Los Angeles. The bidder may succeed only in driving prices higher. The smaller geographic licenses make the possibility of tacitly dividing up the licenses a greater possibility. Not only can the pie be divided along dimensions of perceived value, but punishments can be directed at defectors. For example, PacTel is easily punished for bidding outside of California. A bidder simply tops PacTel's high bid in Los Angeles. Still such tacit collusion is upset by a few value-seeking bidders with deep pockets that do not have clearly specified geographic interests. They have little reason to cooperate and are difficult to punish. However, bidding by these value-seeking bidders may be limited by budget constraints and a lack of existing infrastructure.

\subsection{Bidding Behavior}

Bidding behavior in the MTA auction was dramatically different from that in the narrowband auctions. The bidding was consistently restrained and cautious. Bids were rarely much above the minimum level. Jump bids, rather than being the norm, were the exception. Throughout stages 1 and 2, activity by most firms was near the minimum necessary to maintain eligibility. These differences are displayed in Figure 3, which shows the revenue and bidding activity by round. Revenue, rather than being a nice concave function exhibiting diminishing changes in revenue with each round, is a series of three hills each defined by the auction stages. The first 30 rounds of stage 2 and the first 16 rounds of stage 3 show no tendency for diminishing changes in revenue. Bidding activity in the narrowband auctions followed a pattern of steady exponential decay as bidders dropped out of the auction or cut back demand. In sharp contrast, broadband bidding activity was a sequence of three bursts in activity at the beginning of a stage followed by decay. The decay in stage 1 was especially dramatic. All major bidders held back, simply 
bidding to maintain eligibility. By round 10, activity had fallen to a single bid in Detroit. ${ }^{9}$

Activity was restored to above $30 \%$ with the movement to stage 2 in round 12 . Firms were forced to bid or reduce eligibility. Activity was so steady in the next 18 rounds that in round 31 the FCC raised the bid increment from $5 \%$ to $10 \%$. Over the next 20 rounds activity steadily declined until leveling out at about $7 \%$ in round 51. A drop in the bid increment in round 60 from $10 \%$ to $5 \%$ failed to stimulate activity. Hence, in round 65, stage 3 began. Again bidding activity jumped back to over $30 \%$. Steady bidding by AT\&T and especially WirelessCo kept revenues increasing throughout the early rounds of stage 3.

Of the $\$ 7$ billion raised during the auction, $12.5 \%$ was raised in stage $1,51.8 \%$ was raised in stage 2 , and $35.6 \%$ was raised in stage 3. Despite the importance of stage 3, it is not the case that the earlier rounds served little purpose. Shifts in the allocation of licenses from the end of stage 2 were limited. On licenses covering $76 \%$ of the population, the high bidder at the end of stage 2 won a license in the market. Hence, much of the sorting was accomplished in stage 2 .

\subsection{Why so Cautious?}

There are several explanations for the absence of aggressive bidding in the broadband auction. First, the lower eligibility ratio and the possibility of tacit collusion suggested to firms that prices might be low in certain markets. The matching might occur at low prices. A cautious, patient bidder might save tens of millions by limiting demands early on. Second, because of the high stakes, broadband bidders were more constrained in their behavior. More elaborate control structures were in place and more individuals were involved in the bidding decisions. The narrowband bidders were relatively small, entrepreneurial companies operating in a highly competitive paging industry. In contrast, the MTA broadband bidders were mostly giant telecommunications companies operating in regulated monopolies or a duopoly cellular industry. One would guess that conservative strategies would be more apt to carry the day in such an environment. Third, the incentives for signaling through large jump bids were much less in the broadband auction. PacTel, for example, would gain nothing by jump bidding in Los Angeles. Everyone knows that PacTel had a strong interest in Los Angeles. A jump bid would add little to this belief. In contrast, the jump bids in the narrowband auctions played a role in sorting out the assignments.

Many auction experts were more surprised by the aggressive narrowband behavior than the conservative broadband behavior. There are good reasons for laying back and letting the other firms push prices up. This is precisely why the auction design includes minimum bid increments and activity rules that assure that the auction will move at an acceptable pace. By hiding in the grass, a bidder lets others reveal information, preserves the possibility of tacit collusion, and reduces the possibility of a bidding frenzy.

\subsection{Final Results}

Table 3 shows the final outcome of the MTA auction. For each market, the table gives the population, the round in which the final bids were placed, the winning firms, the marginal bidder (i.e., the last bidder to drop out), and the bids and the prices (\$/pop). ${ }^{10}$ Most of the licenses did not receive final

\footnotetext{
${ }^{9}$ The auction would not have closed if no new bids were received. The FCC would have moved to stage 2 immediately.

${ }^{10}$ In the MTA auction, prices are measured in \$/pop, rather than \$/MHz-pop, since both bands are the
} 
bids until late in the auction. Even by the end of stage 2, only $19 \%$ of the licenses had final bids.

Prices varied a great deal across markets, but varied little within markets. The similarity of prices within a market is clear. The licenses are near-perfect substitutes and the auction design allows bidders to shift between licenses as prices change. Across markets there is no reason to expect similar prices. Chicago, the most expensive market at $\$ 31.90$ per pop, and Guam, the cheapest at $\$ 0.61$ per pop, differ in important ways. Revenues on a per pop basis depend on several factors which vary by market, such as anticipated population growth, income, and cellular use. More importantly, the cost of providing service differs substantially across markets. Buildout costs are much less in densely populated markets that are relatively flat. Chicago is flat and has most of its population concentrated in a small subset of the MTA. Buildout costs are low and the market commands a high price. In contrast, Charlotte ( $\$ 7.27$ per pop) has its population spread throughout a large MTA with hilly terrain. Buildout costs are also low in MTAs like Denver and Salt Lake City where most of the population is in relatively flat areas and coverage can be provided from surrounding mountains.

Buildout costs on average are expected to be at least double the license fees (Salant 1995). Hence, any variation in buildout costs will be magnified in the license fee. Suppose a typical market has a license fee of about $\$ 15$ per pop and a buildout cost of $\$ 30$ per pop for a total cost of $\$ 45$. If a particular market's buildout cost is $50 \%$ above the norm ( $\$ 45$ not $\$ 30)$, then the market would require a license fee of $\$ 0$ to maintain the $\$ 45$ per pop cost. Variation in buildout costs was such that some firms assigned negative values to developing markets with high buildout costs.

Table 4 shows the final outcome by bidder. The bidders are sorted from most to least important in determining prices, where importance is measured by the population coverage of markets in which the bidder either won or was marginal (the last to drop out). 18 of the 30 bidders succeeded in winning licenses. WirelessCo and AT\&T were the two most aggressive bidders. Between them they won 58\% of the available spectrum. $87.3 \%$ of the spectrum was won by the major local and long distance telephone companies. Most of the remainder was won by three other companies: American Portable (a subsidiary of TDS), Western, and Powertel (a large electric utility).

There is a strong correlation between the size of the upfront payment and the amount of spectrum won by a bidder. This association is present in all six auctions. When we regress percent spectrum won with percent upfront payment, we find that the upfront payment is a critical determinant of how much spectrum is ultimately won. The correlation between the upfront payment and the percentage winnings is $78 \%$ in the nationwide auction, $83 \%$ in the regional auction, $93 \%$ in the MTA auction, and $64 \%$ in the Cblock auction. Some of the correlation in the MTA auction is an artifact of the low total eligibility. Some firms with large upfront payments had to win a large share of the licenses. But the correlation is much stronger than required. A bidder with a large percentage upfront payment tended to win an even larger percent of the spectrum. Bidders with small upfront payments tended to win nothing.

The 30 bidders can be split into three broad categories: national bidders, value-seeking bidders, and regional bidders. Table 5 lists the bidders by type and perceived financial strength. For each bidder, the table gives the bidder's influence on price (measured by the total population coverage of the markets in which the bidder either won or was marginal), and a brief description of the bidder's apparent strategy. Most of the bidders had simple strategies, which I term "sincere." They bid on a specific set of markets until prices got too high and then reduced demand. Other bidders, such as GTE, adopted a wait and see strategy, avoiding markets of primary interest until later in the auction (Salant 1995). Still others, such as

same size $(30 \mathrm{MHz})$. 
WirelessCo, had complex strategies in which moves into markets were timed to take advantage of the activity rule.

\subsection{Craig McCaw}

A notable absence in the list of winners is Craig McCaw, bidding as Alaacr. Although McCaw did not win any licenses, he played an important role in several key markets. McCaw apparently recognized that in some markets there might not be enough deep-pocketed bidders for prices to reach full value. By putting down just $\$ 33$ million in earnest money, McCaw gained eligibility to bid in many large markets. At almost no cost (the lost interest on the $\$ 33$ million upfront payment), McCaw was buying the option to step in and snatch licenses that were underpriced because of a lack of competition. $\mathrm{He}$ was an opportunistic bidder, who in the end did not find any opportunities.

To estimate the effect of McCaw's presence, we can look at those markets in which McCaw was the marginal bidder (the last to drop out). One estimate of McCaw's effect on price is the difference between the high bid and the next highest bid without McCaw. In the five markets where McCaw was the marginal bidder, this difference totals $\$ 825$ million (or $\$ 829$ when one includes the effect on pioneer revenues). Most of this difference comes from two markets: New York where GTE dropped out at $\$ 150$ million and Los Angeles where no one else ever bid against PacTel. Due to under bidding, this may overstate McCaw's effect on revenues. For example, even though McCaw was the only bidder to compete with PacTel in Los Angeles, someone else may have stepped in if McCaw was not there. The question is how high another bidder would be willing to go. Los Angeles and New York were too large for the smaller bidders. GTE was the only realistic competitor in these markets. But GTE had little to gain and much to lose by pushing up the prices in Los Angeles and New York.

McCaw's presence was important not only to raise revenue for the government, but also in reducing the possibility of successful tacit collusion. If several markets are going for low prices because of too few deep-pocketed bidders, then the incentive for bidding on other licenses is reduced. A bidder holding an undervalued license is more apt to limit its bidding, because of the possibility that additional bidding will trigger competition for the undervalued license.

Some commentators suggested that Craig McCaw, the largest individual shareholder of AT\&T with a $1 \%$ stake, was simply bidding with AT\&T's interests in mind. McCaw could raise rivals' costs and facilitate tacit collusion by punishing bidders in markets in which AT\&T was ineligible to bid. McCaw's behavior appears inconsistent with this hypothesis. McCaw's bidding in under-priced markets tended to upset tacit collusion, contrary to AT\&T's interest. Furthermore, by pushing prices higher in the nonAT\&T markets, McCaw caused some bidders to switch to AT\&T markets, increasing competition and prices in these markets. In all likelihood, AT\&T would have been better off with McCaw absent.

Further evidence of McCaw's interest in PCS comes from his subsequent investment in Nextel, which offers an alternative to PCS. It seems that McCaw was looking for the best way to stay in the industry. When exceptional values vanished in PCS, McCaw looked to alternatives. Although Nextel benefitted from higher PCS prices, McCaw did not, since the terms of the Nextel deal were negotiated after McCaw left the auction.

\subsection{Strategic Bidding}

The simultaneous multiple-round auction, by revealing information and giving bidders enormous flexibility in responding to information, tends to minimize the need for elaborate bidding strategies. Nonetheless, a simple strategy of bidding up licenses until price exceeds value is probably far from 
optimal. Firms bidding in multiple markets have an incentive to under bid; that is, to bid in fewer markets than they desire at current prices (Ausubel and Cramton 1996, Engelbrecht-Wiggans and Kahn 1995). The bidders face a complex matching problem: who should get which licenses? They have a strong interest in resolving this question before prices get too high. The auction can be thought of as a negotiation process in which bidders begin by making conflicting demands. The auction ends when enough bidders reduce demands, so that excess demand is zero. Signaling is a device to facilitate the sorting. Signaling can take the form of public announcements, such as PacTel's repeated announcements that it would win Los Angeles and San Francisco, or it can be through bidding behavior. Code bidding, double bidding, jump bidding, raising one's own bid, and strategic drops or shifts in bids are all examples of strategic bidding.

Code bidding involves using the last few digits of a bid to signal information to a rival. For example, on markets of primary interest, GTE ended its bids with 483, which spells "GTE" on a telephone keypad. American Portable, a subsidiary of TDS, signaled interest in some markets by spelling "TDS" (837) in the last three digits. A more collusive use of a code bid is to tell the bumped rival where to move. A bid of $\$ 14,500,039$ on Tulsa could tell the bumped bidder to move to market 39 (El Paso). Alternatively, the code bid can threaten the bumped bidder to drop out of the market or face retaliation in another market. If the firm bumped by a bid of $\$ 6,200,024$ holds a high bid in market 24 , the bidder may be telling the bumped firm, "Drop out of this market or expect punishment in market 24." There was some use of code bidding in the MTA auction, but the codes were not as obviously collusive as the last two examples. Some bidding teams decided that such codes were too blatant and ran the risk of antitrust action by the Justice Department.

Double bidding - bidding on both licenses in a market - became a common strategy in stage 3 . If the market is contested (there are three or more bidders active in the market) or prices are low, the double bid is a cheap way to maintain eligibility. It also facilitates tacit collusion by maintaining eligibility without moving into a rival's territory. PrimeCo made use of the double bid in the early rounds of stage 3 . WirelessCo made extensive use of the double bid, preserving more than 20 million of eligibility through much of stage 3 .

The double bidding let WirelessCo store eligibility for later use. This was important because it gave WirelessCo flexibility in deciding when to attack in certain markets. A good example was WirelessCo's behavior toward McCaw. WirelessCo patiently waited for $\mathrm{McCaw}$ to use waivers and drop eligibility before bumping McCaw in New York in round 70. In round 74, McCaw dropped out of New York, leaving WirelessCo as high bidder, but bumping WirelessCo in San Francisco in the process. However, McCaw could not return to New York unless it was bumped or withdrew in San Francisco. Hence, WirelessCo left McCaw alone in San Francisco. By round 87, McCaw had used all its waivers and dropped 18 million in eligibility, preventing a return to New York. WirelessCo immediately returned to San Francisco.

Double bidding can help a bidder postpone an attack in particular markets, but it is not without costs. Double bidding exposes the bidder to withdrawal penalties and it may increase prices in the markets with double bids. 8 of the 51 markets closed with a double bidder dropping one of its two bids. Hence, the double bidder often pushed price above what it would have been without the double bid.

Only well into stage 3 did we begin to see jump bidding. ${ }^{11}$ WirelessCo placed four jump bids in round

\footnotetext{
${ }^{11}$ Exceptions were the two jump bids in Los Angeles by McCaw, but these simply pushed the Los Angeles price back in line with other major markets. Southwestern Bell also placed some jump bids in stage 2 .
} 
79, double bidding in two uncontested markets (Pittsburgh and Kansas City). It did the same thing in two markets in round 81 (Des Moines and Oklahoma). These jumps were difficult to understand. They did suggest that prices were still low in several markets or else WirelessCo was throwing money away. WirelessCo must have expected further activity in these markets. Indeed, in three of the four markets, there was additional activity. Only in Oklahoma did WirelessCo face a withdrawal penalty as a result of the large double jumps. In two of the markets (Pittsburgh and Des Moines), it paid one bid increment less than the other winner. WirelessCo's double jumps were probably unsuccessful. The message they sent was confusing and led to significant overbidding in Oklahoma.

Although jump bids were rare, there were a few instances where markets closed after a jump bid. For example, PrimeCo's final bid in Chicago was a jump $\$ 11.7$ million above the minimum bid. WirelessCo dropped out in response. It is impossible to know whether PrimeCo left money on the table or whether the jump induced WirelessCo to drop out.

Strategic shifts or drops can be used to facilitate collusion. In a strategic shift, a bidder shifts to another license to keep prices in other markets from escalating. If firms $\mathrm{X}$ and $\mathrm{Y}$ are competing in market 1 and firm $\mathrm{X}$ is in market 2 , then $\mathrm{Y}$ switches out of market 1 and into market 2, implicitly telling $\mathrm{X}$ to drop 2 to prevent further competition in market 1. In a strategic drop, a bidder drops a license, prompting a reciprocal drop from a competitor. If $\mathrm{X}$ and $\mathrm{Y}$ are competing in markets 1 and 2, then $\mathrm{Y}$ drops market 1 , implicitly telling $X$ to drop market 2 . Strategic shifts and drops have two difficulties, which limit their use. First, the implicit message is much less clear than with a gift withdrawal or code bidding. Second, strategic shifts and drops are only effective once the competition is down to two bidders. Prices at this point may already be high. There is little evidence that strategic shifts or drops were used successfully to limit competition.

In special circumstances, raising one's own bid may be a good strategy. If the high bidder believes that the remaining competitor would be willing to bid up one bid increment, but not two, then the high bidder may benefit from raising its own bid. PrimeCo successfully anticipated GTE's final bid in Jacksonville. PrimeCo raised its own bid in round 108, topping GTE's final bid in the same round. A good example of the cost of such a strategy is Powertel's \$2.5 million raise of its own bid in Jacksonville in round 110. Powertel expected GTE to come back in Jacksonville, but GTE had decided to drop the market. Another costly example is WirelessCo's experience in San Francisco. In round 97, WirelessCo, Alaacr, and American Portable were still competing for the remaining San Francisco license (it was assumed that PacTel would win the other). WirelessCo was the high bidder and had just made the gift withdrawals of Tampa and Houston to get American Portable to move off San Francisco. WirelessCo expected Alaacr and perhaps American Portable to come back in San Francisco. In anticipation of this competition, WirelessCo raised its own bid by $\$ 14.4$ million. But the competition did not materialize. Both Alaacr and American Portable dropped out of San Francisco.

For the most part, bidders tended to bid on the cheaper of the two bands. However, in several cases this rule was not followed. There are two reasons for bidding on the more expensive license. First, the bidder may prefer one band over the other, because it expects to win neighboring licenses of the same band. AT\&T attempted to get band A in most of its markets; PrimeCo favored band B. Second, it may make sense to bid against the weaker bidder to avoid punishment in other markets. A bid against the strong firm may upset tacit collusion and drive prices higher. In four markets, the final bid was on the more expensive license against a smaller (weaker) bidder. AT\&T bumped PCS America in Buffalo rather than the slightly cheaper license held by WirelessCo. In Detroit, WirelessCo bumped American Portable, rather than AT\&T although it was $\$ 1$ million more. In Atlanta, AT\&T bumped Powertel, not GTE although it was \$4.3 million more. In Minneapolis, WirelessCo bumped Continental although it was \$1.3 
million more than American Portable. One possible explanation for this behavior is that the bidder was concerned with retaliation in other markets. Otherwise, bidding against the strong bidder is the better strategy. It saves money and raises the cost of a strong competitor.

Strategic bidding played a more important role in the MTA auction than in the narrowband auctions, because of the reduced competition. However, even in this auction, much of the strategic bidding did not seem to improve the bidder's position. Subtle signaling was especially ineffective.

\subsection{Bid Withdrawals}

Bid withdrawals are another example of strategic bidding. The purpose of allowing withdrawals is to let bidders back out of failed aggregations. There were 21 withdrawals in the auction. All but two were in stage 3. However, none of the withdrawals seems to be motivated by an exit from a failed aggregation. Rather the withdrawals appeared to be for some other strategic purpose.

There are several reasons for withdrawing a bid:

- To back out of a failed aggregation. The withdrawal follows being bumped on complementary licenses. The bidder either drops eligibility or shifts to another set of complementary licenses.

- To increase flexibility in the next round of bidding. A bidder with little free eligibility might want to shift among licenses in the next round.

- To maintain eligibility or raise rivals' costs. A bidder might engage in a fight for a license it is not truly interested in. It then withdraws when the competitor drops out.

- To maintain eligibility without raising prices. A bidder withdraws from a license and then places a minimum bid. When repeated, this maintains eligibility, but prices do not rise, so long as a competitor places the minimum bid. The withdrawal signals to others that the bidder is not truly interested in the license.

- To make room for another bidder to drop down. In a fight with another bidder, a bidder might withdraw to suggest that the competitor move to the withdrawn license rather than continue the fight. This facilitates tacit collusion by offering a gift and then lowering the cost of punishment. It is easier to punish bad behavior by the bidder that takes over a withdrawn license. A raise by the bidder that withdrew is essentially costless, since the withdrawn bid amount is already committed.

Table 6 shows the 21 bid withdrawals in the auction. WirelessCo made 11 of the 21 withdrawals. Only 6 withdrawals resulted in penalties. The $\$ 14.836$ million in penalties were paid by WirelessCo ( $\$ 14.514$ million) and American Portable ( $\$ 0.322$ million). Most of the withdrawals were to maintain eligibility (11 of 21) or increase flexibility (5 of 21). WirelessCo's extensive double bidding resulted in only two withdrawals (Minneapolis and Oklahoma) with penalties of $\$ 3.851$ million. None of the withdrawals appeared to be caused by predatory bidding (bidding up a license to raise a rival's costs).

One pair of withdrawals was apparently intended as a gift to entice a competitor to shift to the withdrawn licenses. In round 97, WirelessCo withdrew from Tampa and Houston, hoping that American Portable would take this gift and move off San Francisco. American Portable accepted the gift, moving down to Tampa and Houston in the next round. WirelessCo's gift cost it $\$ 8.505$ million in penalties, but this is less than one bid increment in San Francisco.

A possible implication of the withdrawals in stage 3 is that some licenses might go unsold. Late in stage 3, bidders might not have the eligibility to pick up withdrawn licenses. Fortunately this did not happen. Most of the withdrawals near the end of the auction were to increase flexibility in the next round. 
If the licenses were not picked up by a competitor, then the withdrawing bidder picked up its own withdrawals.

\section{The C-Block Auction}

The next auction was for the third (and final) $30 \mathrm{MHz}$ block of broadband spectrum, the C-block. 493 BTA licenses were sold to small businesses (annual revenues less than $\$ 40$ million). Large firms were not eligible to bid. Although this auction was to start shortly after the MTA auction finished, the auction was delayed for 6 months in the courts. ${ }^{12}$ The C-block auction finally began on December 18, 1995, and concluded nearly 5 months later on May 6, 1996, after 184 rounds. Revenues net of the $25 \%$ bidding credit were $\$ 10.2$ billion, more than double the prices in the MTA auction.

Figure 4 displays the bidding activity and revenue by round. Bidding activity was much higher than in the MTA auction - so much so that the stage transitions were hardly noticeable. Bidders did not hold back as they did in the MTA auction. Prices quickly escalated to well beyond MTA prices. Early activity was especially strong in the major markets. This is consistent with the major markets (e.g., Chicago) being key to a synergistic combination in a broader area (the midwest). Bidders wanted to resolve the major markets before going after the smaller complementary markets. Bidding in the second half of the auction was almost exclusively on these smaller markets.

Many were shocked by the high prices. What accounted for average net prices of $\$ 39.88$ per pop in the C-block, compared with $\$ 15.54$ per pop in the MTA auction? There are two main explanations: installment payments and competition.

The small bidders in the C-block auction were given attractive payment terms to compensate for difficulties in raising capital. C-block winners pay 5\% at the end of the auction, $5 \%$ at the time of award, and then ten years of installment payments at the 10-year Treasury note rate. The quarterly installments cover interest only for the first six years. During the auction the 10 -year T-note rate was about $6.5 \%$. If we assume a cost of capital for the firm of $14 \%$, then this $7.5 \%$ spread amounts to an additional bidding credit of $32 \%$. With a $16.5 \%$ cost of capital $(10 \%$ spread), the installment payments give an additional bidding credit of $40 \%$. Hence, the C-block price of $\$ 39.88$ becomes $.6 \cdot 39.88=\$ 23.93$.

\footnotetext{
${ }^{12}$ On March 15, 1995, the U.S. Court of Appeals in the District of Columbia stayed the auction until the court could hear the case brought by Telephone Electronics Corporation (TEC), a rural telephone company. TEC claimed that it was unfairly excluded from the auction and questioned the constitutionality of bidder preferences for women and minorities. In early April, TEC withdrew its lawsuit in a settlement with a third-party. PCS PrimeCo, a major bidder in the MTA auction, agreed to give TEC what it wanted. The auction, which was scheduled to begin in June 1995, was postponed until early August. The auction was postponed again when the June 12 Supreme Court decision in Adarand $v$. Pena made it likely that the race and sex preferences would not survive a constitutional challenge. The FCC modified the rules to give all small businesses, regardless of race or sex, the same $25 \%$ price preference and attractive payment terms. Previously, only women or minority controlled firms were eligible for the most attractive terms. The auction was rescheduled to August 29. The C-block auction was stayed a third time on October 18, in response to Radiofone's challenge of the PCS/cellular cross-ownership rule, which limits the amount of broadband PCS spectrum that a cellular licensee can acquire in its cellular market. On October 25, Justice Stevens, Circuit Justice for the Sixth Circuit, vacated the stay. On October 30, the full U.S. Supreme Court declined to overturn Justice Stevens' Order dissolving the Sixth Circuit stay.
} 
This calculation ignores the option value created by the back-loaded installment plan. To the extent that there is uncertainty about the value of spectrum, the option of default in case spectrum has a low value makes a license worth more than its expected value. Nonetheless, an effective bidding credit from installments in the range of 30 to 50 percent seems about right. At $40 \%$, the installment payments account for about $\$ 16$ of the $\$ 24$ spread between the $\mathrm{C}$ and A-B prices.

The second important factor explaining the higher prices was the much greater competition in the Cblock. Competition in the MTA auction was weak in several of the major markets. In contrast, competition in the C-block auction was strong in all markets. The eligibility ratio (total eligibility in pops divided by total pops being auctioned) was 6.75 , compared with 1.93 in the MTA auction. There were 255 bidders compared to 30 in the MTA. 89 bidders won licenses, rather than 18 in the MTA.

Ausubel and Cramton (1996) demonstrate that larger bidders have a greater incentive to reduce demand in order to keep prices low. Hence, having a large number of small bidders is more competitive than a small number of large bidders, holding the eligibility ratio fixed. Moreover, competition may have been heightened by the fact that in many cases the bidders were startups that would be out of a job if licenses were not won.

The importance of competition in determining prices is seen by comparing prices in the four largest MTAs (Table 7). The C-block prices have been discounted by $40 \%$ to account for the installment payments. Notice that the C-block prices are fairly close. In contrast, the Chicago MTA price is well above the other MTA prices. In Chicago, all three nationwide bidders (WirelessCo, AT\&T, and PrimeCo) were eligible to bid; whereas, in New York and San Francisco, only WirelessCo was eligible. This lack of competition in New York and San Francisco seems the only compelling explanation for the low prices in these markets, relative to Chicago. Judging from these markets, the discounted C-block prices are not out of line with the prices on the more competitive markets in the MTA auction. This conclusion is supported by the price regression in Ausubel, et al (1996). The strongest determinant of prices in the MTA auction was the level of competition, measured as the eligibility in the market over the total eligibility. In the Cblock auction this variable was insignificant, since all markets were competitive.

Table 7. Price Comparison in Major Markets (\$ per person in 1994)

\begin{tabular}{ccc}
\hline \hline & $\begin{array}{c}\text { C-block price with 40\% } \\
\text { installment discount }\end{array}$ & MTA price \\
\hline Market & 27.74 & 16.52 \\
Los Angeles & 26.47 & 24.05 \\
Chicago & 27.18 & 30.40 \\
San Francisco & 31.54 & 16.10 \\
\hline \hline
\end{tabular}

The high C-block prices raised the concern that some winners may default. Indeed, the fourth largest winner (BDPCS) failed to make the initial 5\% down payment, defaulting on 17 licenses for which it bid $\$ 874$ million. BDPCS was expecting the down payment to come from US West, but apparently US West changed its mind about funding BDPCS. The FCC quickly decided to reauction the licenses. The reauction began on July 3 and ended on July 16 after 25 rounds. By the fifth day of bidding (round 16), net revenues of the reauctioned C-block licenses already matched the $\$ 874$ million total from the default. On day six, 
the auction was nearly over with two consecutive rounds with no new bids (the auction remained open, because at least one firm submitted a proactive waiver). Final net revenue was $\$ 905$ million, $3 \%$ greater than in the initial auction. In all but four markets, the reauctioned licenses sold for within $25 \%$ of the original prices.

Aside from this default, which was quickly corrected, the auction was successful. There surely will be future defaults, given the large number of small businesses that won licenses. However, this must be expected in an auction involving such substantial sums and yet small upfront payments.

This auction demonstrated the feasibility of conducting simultaneous multiple-round auctions with hundreds of licenses and hundreds of bidders. Although the auction was long, the long duration gave bidders and capital markets time to make difficult decisions that determined the assignment. The speed of the reauction indicates the importance of price uncertainty in determining auction duration.

\section{Auctioning Encumbered Licenses}

Two other auctions were conducted at the same time as the C-block auction. The MDS (wireless cable) auction had the same structure as the C-block: a single license in each of 493 BTAs. In the SMR auction, 20 licenses were sold in each of 51 MTAs (1020 licenses in total). Both of these auctions involved the sale of heavily encumbered licenses. The FCC had previously awarded numerous MDS and SMR licenses of limited geographic scope. In these auctions, winners must protect incumbents against interference. Hence, what was sold was like swiss cheese with large holes in some of the most desirable areas. As a result, MTA and BTA populations were no longer a relevant measure of the size of a license. Instead, the FCC used "bidding units," which were an attempt to measure the size of the effective population covered by a license.

Both auctions attracted a large number of bidders (155 for MDS and 128 for SMR), but the initial eligibility ratios (3.6 for MDS and 2.4 for SMR) were well below that of the C-block. Figures 5 and 6 show the bidding activity and revenue by round. The stage transitions are noticeable in both, suggesting a mild tendency for the bidders to hold back. However, neither had the large swings in activity found in the MTA auction.

The discontinuous jump in revenues in round 9 of the SMR auction was the result of a mistaken bid. Atlanta Trunking intended to bid $\$ 125,025$, but added three extra zeros, and submitted the bid of $\$ 125,025,000$. Atlanta Trunking immediately withdrew the bid, but according to the FCC rules was liable for a withdrawal penalty well in excess of $\$ 100$ million. This was the first mistaken bid in FCC spectrum auctions, but not the last. Three mistaken bids were placed in the C-block auction. MAP added an extra zero to its bid in round 10. Then only two rounds later, PCS 2000 made the same mistake on a larger license. Finally, in round 38, Georgia Independent added an extra zero as well. Given that over 60,000 bids were placed in these three auctions, it is not surprising that a few mistakes were made. The FCC responded to these mistaken bids by modifying the software to warn the bidder if a bid appears to be a mistake. In addition, they adopted a rule for mistaken bids. The rule limits the size of the penalty in the event of a mistaken bid, but still imposes a penalty sufficient to discourage mistakes.

In the SMR auction, the incumbents expressed concern that they might be at a disadvantage in the auction. They argued that they were vulnerable to speculators, to predatory bidding, and would have less flexibility in stage 3 to move to unencumbered licenses. I was of the opinion that incumbents were at an advantage. The incumbent would be buying areas that complement its existing licenses; whereas, the nonincumbent would be buying swiss cheese with substantial interference problems. As it turned out, incumbents paid significantly less than nonincumbents. 


\section{Assessing the Auction Design}

Since we do not observe the values firms place on licenses, it is impossible to directly assess the efficiency of these auctions. Nonetheless, we can indirectly evaluate the auction design from the observed behavior. To aid in comparing and assessing the auctions, Table 8 presents summary statistics for each auction. These statistics are discussed throughout this section.

\subsection{Extensive Information was Revealed by the Bidding}

Two essential features of the design are (1) the use of multiple rounds, rather than a single sealed bid, and (2) simultaneous, rather than sequential sales. The goal of both of these features is to reveal information and then give the bidders the flexibility to respond to the information. This should reduce the winner's curse and more importantly facilitate efficient aggregations. Proponents of sequential auctions have argued that the information revealed in a simultaneous auction is of little help to the bidders, because it is only preliminary information. The final outcome may be far from the current state, even near the auction's end. Using the data from the auctions, I evaluate both the quality of the information revealed in the auction and the ability of firms to respond to the information. There are two dimensions to the information: the assignment of licenses and the prices of the licenses. Each is considered in turn.

As observed earlier, the upfront payment is an excellent indicator of the quantity of spectrum won. It, however, tells us nothing about which licenses a firm will win. For this bidders must look at the bids during the auction. In each of the auctions, much about the final assignment was determined well before the auction's end.

In the nationwide auction, the high bidders in round 28 were the same as in the final assignment 19 rounds later, except for one license. Only a few questions remained, such as which firms would get the two 50s. Well before round 28, it was clear who was likely to win the 50/50s and 50/12s. The assignment in the regional auction settled even more quickly. By round 10, the high bidders were the same as in the final assignment 95 rounds later.

One might expect that the MTA auction would present a different picture, because of the rampant under bidding in stages 1 and 2 of the auction. However, despite this under bidding, the current assignment revealed a great deal of information about the final assignment. Figure 7 tracks by round the fraction of current high bidders (pop weighted) that eventually win in their current markets. This fraction, which hits $50 \%$ in the second round, gradually increases throughout the auction. At the end of stage 2 (round 64), 76\% of the current high bidders were still high at the end of the auction (round 112). The major exceptions were in New York, Chicago, and Washington.

The clarity of the assignments stems from the fact that most bidders had focused interests. They bid on a relatively small set of licenses throughout the auction, although they were typically eligible to bid on much more. As a result, the number of active bidders in each market was small. Table 9 shows the distribution of the number of excess bidders in each market. It is based on the number of bidders that were active in the market after stage 2. A typical market had 3 excess bidders (5 bidders in total) over the entire auction. By the end of stage 2 , there was only a single excess bidder in a typical market. 
Table 9. Distribution of Excess Bidders in Markets (Population Weighted)

\begin{tabular}{|c|cccccc|}
\hline Number of excess bidders in market & 0 & 1 & 2 & 3 & 4 & 5 \\
\hline Percent of markets over entire auction & 0 & 13 & 20 & 41 & 20 & 6 \\
Percent of markets after stage 2 & 15 & 42 & 30 & 11 & 1 & 0 \\
\hline
\end{tabular}

The current bids provide good information about final assignments, but what about prices? Again, in all six auctions, current prices give good information about relative prices at end of auction. Figure 8 displays the correlation between current and final prices throughout the MTA auction. Initial bids are only modestly correlated with final prices $(30 \%)$. This correlation does not increase until stage 2 , but then increases sharply in the early rounds of stage 2 , reaching $62 \%$ by round 21 . From round 21 , the correlation increases steadily throughout the remainder of the auction. The correlation is $83 \%$ at the end of stage 2 .

The remaining question is whether bidders have the flexibility to act on the information. By the time firms have a good sense about prices and the assignment, they may not have sufficient eligibility to respond. Clearly this was not the case in the narrowband auctions. In the nationwide auction, firms maintained their full eligibility throughout the auction, since the auction never moved out of stage 1 . In the regional auction, the assignment and prices settled early. Bidders had good information about the outcome throughout stage 2 and had plenty of flexibility to shift among licenses.

The biggest concern about flexibility came in the MTA auction, where much of the action did not occur until stage 3 . Figure 9 shows the eligibility ratio by round. Starting at 1.93, the eligibility ratio fell to 1.53 by the end of stage 2 . Hence, at the end of stage 2, there is good information about prices (83\% correlation with final prices) and assignments (76\% eventually win), and yet plenty of eligibility (1.53) to shift among licenses in response to this information. This flexibility was observed in the firms' behavior through most of stage 3. Firms bidding on several licenses were able to move among different sets of licenses, only losing an insignificant amount of eligibility. American Portable and others made such shifts in several rounds. The fact that there was much movement among licenses as prices changed suggests that the simultaneous design was important in determining the outcome.

The extensive information about prices and assignments is not simply a result of markets closing early. Figure 10 shows the fraction of licenses by round with final bids (pop weighted). At the end of stage 2 only $19 \%$ of the licenses had received final bids. By round 74, the correlation between current and final prices was up to $89 \%$, even though final bids had been received on only $25 \%$ of the licenses. A great deal of bidding was still to take place, but the information about the eventual outcome was excellent.

\subsection{Similar Items Sold for Similar Prices}

An advantage of the simultaneous ascending-bid design is that it tends to generate market prices. Similar items should sell for similar prices. There is strong evidence of this in all six auctions. In the nationwide auction, the price differences among similar licenses were at most a few percent and often zero. In the regional auction, price differences were larger, but still small with the exception of one license with a bid withdrawal late in stage 3 . The importance of forming nationwide aggregations within the same band was probably the source of the larger differences in prices. In the MTA auction, only the A and B licenses within the same market are directly comparable. A and B prices differed by less than one bid increment in 42 of the 48 markets. In the six markets where prices differed by more than an increment, 
three involved withdrawals (two to maintain eligibility and one gift) and three were to avoid strong bidders, which was especially important if the strong bidder favors one band.

The generation of market prices is important from an efficiency viewpoint. In addition, it contributes to a sense among the bidders (and observers) that the auction is fair. Most bidders in all six auctions walked away feeling satisfied by the process, even if they were disappointed by the outcome.

The simultaneous stopping rule is an important factor in achieving market prices and efficiency. Market-by-market closing would not give the bidders sufficient flexibility. With market-by-market closing, the auction is essentially a sequential auction with endogenous order. A license may close by the time a bidder wants to shift to it. This possibility was seen in each of the auctions. It was common for licenses to have no bids for several rounds followed by steep increases in price. For example, in the nationwide auction, bids on the 50/50s stopped for seven rounds (from round 20 to 26) at $\$ 70$ million, but then increased to $\$ 80$ million. Prices on the 50/12s had to increase before bidding could continue on the 50/50s. This tendency for long pauses in activity in particular markets was even more pronounced in the MTA auction.

\subsection{Efficient Aggregations were Formed}

Valuations depend on the set of licenses won. Hence, it is important to use an auction form that allows bidders to express these value interdependencies. Such a design would encourage the formation of efficient aggregations. Supporters of the simultaneous ascending-bid design argued that bidders would have sufficient flexibility to express valuations for combinations of licenses, even without package bids. However, others argued that package bids would be essential to achieving efficiency. They feared the exposure problem would discourage bidders from going after synergistic gains. Evidence from the auctions suggests that bidders were able to form efficient aggregations without package bids.

In the nationwide auction, the aggregation problem was simple. Bidders acquiring multiple bands preferred adjacent bands. In all cases, bidders acquiring multiple bands were successful in winning adjacent bands (PageNet won bands 1 and 2, and McCaw won bands 3 and 4).

In the regional auction, the aggregation problem was more complicated. Several bidders had nationwide interests. These bidders would have to aggregate all five regions, preferably all in the same band. The bidders were remarkably successful in achieving these aggregations. Four of the six bands sold as nationwide aggregations. Bidders were able to win all five regions within the same band. Even in the two bands that were not sold as nationwide aggregations, bidders winning multiple licenses won geographically adjacent licenses within the same band. The regional auction demonstrated that in this setting it is possible to build large aggregations without allowing package bids.

Large aggregations also were formed in the MTA auction. Overall, there was a tendency for bidders to win the same band when acquiring adjacent licenses. AT\&T was high bidder on the A band in its top markets and PrimeCo was the high bidder on the B band in its top markets. The large aggregations won by WirelessCo, AT\&T, and PrimeCo appear to have efficient geographic coverage when one includes cellular holdings. WirelessCo won nationwide coverage except for a single strip of licenses from Cleveland to Tampa and a few other holes (most notably Chicago). PrimeCo won nationwide coverage except for a single block of licenses in the central U.S. Likewise, AT\&T was able to fill its cellular holes except for three regions. The absence of package bids did not seem to prevent firms from forming efficient aggregations. However, it is certainly possible that efficiency was reduced, because of under bidding. High-value bidders may have dropped out of markets too soon to keep prices on other markets from escalating. 
Further evidence of efficient aggregations comes from the absence of bid withdrawals. There were no withdrawals in the nationwide auction. The two withdrawals in the regional auction were minor. They were caused by strategic bidding unrelated to a bidder backing out of a failed aggregation.

Withdrawals in the MTA auction did not suggest aggregation failures. The withdrawals through stage 2 were of no importance. There was an increase in withdrawals in stage 3, but they were mostly motivated from efforts to maintain eligibility, rather than by aggregation failures. A few were attempts to end competition in other markets. If successful, such attempts might reduce efficiency, but they only succeeded in one case. No withdrawals were to back out of failed aggregations. Exposure, then, did not seem to be a problem preventing efficient aggregations.

The C-block auction had 50 withdrawals out of nearly 30,000 bids. Most of these occurred early in the auction. Intouch, for example, made 12 withdrawals in the first 10 rounds, apparently for some signaling purpose. There were no withdrawals in the last 55 rounds of bidding.

Certainly there are settings in which the exposure problem is severe and efficiency is destroyed by not allowing package bids. Experimental evidence is given in Bykowsky, et al. (1995). These tend to be settings with extreme synergies, where a missing piece makes the collection worthless. Real estate projects and room on the space shuttle have this character. However, the synergies in PCS licenses are much less severe. MTA licenses are sufficiently large to capture much of the regional synergies. There is some benefit to having adjacent licenses and there may be other marketing or network synergies, but they are not $0-1$. Those favoring package bids may have overestimated the extent of the exposure problem.

Ausubel, et al. (1996) analyze the MTA auction data to see if there is evidence that synergies caused bidders to pay more for adjacent licenses. They find no such evidence, which suggests that the exposure problem probably did not hamper the formation of efficient aggregations.

\subsection{Tacit Collusion was Limited}

The simultaneous multiple-round auction gives bidders a great deal of information and provides enormous flexibility in responding to this information. In a competitive auction, this information and flexibility should improve efficiency, but it also opens to the door to more collusive strategies. Is there any evidence of collusion in the early PCS auctions? There are two main concerns: limiting competition through alliances, followed by tacit collusion during the auction.

There was no evidence of collusion in either the nationwide or regional auctions. Alliances were unimportant in the nationwide auction. The successful firms bid on their own. In the regional auction, alliances were formed between designated entities and established paging companies. The alliances transformed weak bidders into strong companies capable of competing with the industry leaders. Bidding was aggressive and competitive throughout both narrowband auctions. Marginal bidders dropped out only after long fights with the eventual winners. Jump bidding, although pervasive, seemed ineffective at steering competitors to other licenses. Prices were higher than many predicted. Even when excess demand was small, bidders were unwilling to scale-back demands in order to close the auction at substantially lower prices.

Collusion was much more of an issue in the MTA auction. The PrimeCo alliance presented the biggest problem. It transformed four deep-pocketed bidders with extensive market eligibility into one

deep-pocketed bidder with limited market eligibility. It created the possibility of slight competition in some major markets, such as New York and Los Angeles, and reduced competition in other markets. In contrast, the WirelessCo alliance probably increased competition by creating a strong nationwide bidder from companies that would have been much weaker on their own. 
The PrimeCo alliance greatly increased the chances of successful tacit collusion. This is the primary explanation for the rampant under bidding in the early stages of the MTA auction. Given the possibility that the matching could occur at low prices, there was no incentive for firms to bid aggressively. The low activity requirement in stages 1 and 2 meant that bidders could bid well under their true demands and yet preserve most or all of their eligibility. As such, firms tended to limit their bids to what they wanted most.

Fortunately, tacit collusion is easily upset. It requires that all the bidders reach an implicit agreement about who should get what. With thirty diverse bidders unable to communicate about strategy except through their bids, forming such a unanimous agreement is difficult at best. Although some bidders had clear interests in a few licenses, other bidders like Alaacr and American Portable simply were looking for value. These value-seeking bidders can have large demands at low prices and are hard to punish. In addition, the nationwide goals of WirelessCo, AT\&T, and PrimeCo were incompatible. Not all three could succeed in forming a nationwide aggregation. How much should each cut back to allow room for the other two, as well as the smaller bidders? Disagreements were bound to arise and these disagreements would limit tacit collusion.

Fears of collusion peaked in round 10 of stage 1 when bidding activity plunged to just a single bid in Detroit despite bargain prices. But with the onset of stage 2, bidding activity jumped back up and remained strong. Bidders refused to cut eligibility until well into stage 2 . Sorting out who should get what was not going to be accomplished without the price mechanism. Nonetheless, it was clear that stage 3 would be needed to push prices up. By round 60, activity had once again dropped below 10\%. Many bidders could maintain eligibility in stage 2 by simply sitting on their high bids.

Strong bidding early in stage 3, especially by WirelessCo and AT\&T, put fears of tacit collusion to rest. These firms needed to cut eligibility significantly for the auction to close and neither expressed any interest in doing so. The auction did not end until the average price surpassed government estimates. In a 1992 study, the Congressional Budget Office estimated prices to be between $\$ 3.50$ and $\$ 15.00$ per pop. In 1994 , the Office of Management and Budget estimated a price of $\$ 12.47$ per pop compared with the actual average price of $\$ 15.54$ per pop. Estimates based on recent cellular transactions would be much higher, but it is difficult to unbundle the license value from the value of the network and existing customers.

Narrowband prices (\$3.10 per MHz-pop in the nationwide auction and \$3.46 in the regional auction) were about six times higher than broadband prices ( $\$ .52$ per MHz-pop). However, this is not evidence of collusion in the MTA auction. The narrowband and broadband prices are not comparable, since it would be difficult to use broadband spectrum for narrowband applications. The imbalance simply reflects the different supply and demand conditions in the two markets. It does suggest that the FCC should go ahead with its plans to allocate more narrowband spectrum.

Although tacit collusion failed overall, there may have been some markets where bidders dropped out early to improve the outcome in other markets. For example, American Portable decided to drop out of San Francisco in response to WirelessCo's withdrawal in Tampa and Houston. However, WirelessCo raised its own bid in San Francisco in the round that American Portable dropped down to Tampa and Houston, so this "tacit collusion" was far from perfect. In addition, WirelessCo rebid in Houston later in the auction, bumping American Portable. After a careful review of the bidding, I was unable to find any clear cases of successful tacit collusion.

In those markets that appear to be especially good values (New York, Los Angeles, and San Francisco come to mind), the critical feature seems to be an absence of deep-pocketed bidders. My assessment is that the PrimeCo alliance had more to do with these good values than the success of tacit collusion. 
The auction outcome might have been radically different without the value-seeking bidders, especially Craig McCaw and American Portable. There was close to too little competition in the MTA auction. It is in precisely such circumstances that the simultaneous multiple-round auction is most vulnerable to collusion. In future auctions, it may make sense to reduce collusion risk by limiting alliances among major players in the industry. Such restrictions are common. For example, the top oil companies are not allowed to partner in oil lease auctions. However, it is not at all clear what rule the FCC could have adopted to prevent the PrimeCo alliance and yet encourage synergistic alliances. Formulating general rules would be complex if not impossible. Preventing such alliances on a case-by-case basis would likely delay the auctions and lead to litigation.

\subsection{The Auction Durations were Reasonable}

An important advantage of auctions is their ability to quickly assign licenses to high value uses. The sooner licenses are assigned, the sooner companies can provide services demanded by consumers. Hence, in judging the auction design, we must consider how long it takes to conduct the auction.

Certainly the narrowband auctions were concluded in a timely manner. The nationwide auction took one week and the regional auction concluded in two weeks. Other auction designs could assign the licenses more quickly, but given the importance of the licenses to the firms involved, a more hasty process would be foolish. Companies needed time to think through their options. The short auction durations were possible in these auctions, because of the small number of licenses up for auction (10 in the nationwide and 30 in the regional) and the relatively low stakes. This meant that many rounds could be conducted in a day. Toward the end of the auctions, when bidding activity was low and few decisions were being made, more than one round occurred each hour.

The MTA broadband auction concluded after about three months. This may seem like a long time, but given the magnitude of the decisions involved three months is a modest duration. The speed of the auction was limited by the large number of licenses (99) and the very high stakes. The auction can only go as fast as the bidder that needs the most time. WirelessCo's bidding was especially complex, because of the large number of licenses it was interested in. WirelessCo urged the FCC not to do more than two rounds per day. It was hard not to listen to WirelessCo's plea, since it was the largest bidder and had a legitimate concern.

Probably the largest cost of the three month duration is in postponing subsequent auctions. The remaining broadband auctions cannot begin until after the MTA auction. Companies need to know the MTA outcome before forming alliances and attracting investors. However, the cost associated with a three month delay is probably minimal. Companies also need time to develop plans and get capital in line.

The final three auctions, with many more bidders and licenses, took about four months, 180 rounds, and 80 days to complete. All three auctions had long final tails that involved few bids and little change in revenue or assignment. The FCC did well to shorten this tail by conducting many rounds per day. By the end, 8 or more rounds per day were held in each auction.

Certainly compared with prior methods of assignment the auctions have been successful. Even with streamlined comparative hearings, it took the FCC an average of two years to award thirty "non-wireline" cellular licenses (licenses not limited to local telephone companies). After the FCC switched to lotteries in cellular service, the average time to award a non-wireline license decreased to about one year. With auctions, the average time to award licenses has been less than a year. Of the ten nationwide narrowband PCS licenses, seven were awarded in under two months and the remaining three in under five months. The thirty regional narrowband PCS licenses were awarded in approximately three months. The 99 MTA 
broadband PCS licenses took three months and the licenses were awarded in four months from the close of the auction. It should be noted that the length of an auction depends in part on policy decisions and that faster is not always better. In the case of the MTA broadband auction, most of the auction was conducted with two rounds per day so that bidders would have sufficient time to evaluate the results of the previous round and plan their bidding strategy.

\subsection{Minimum Bid Increments were Needed}

Minimum bid increments play an important role in controlling the pace of the auction. If set too high, the increments choke off bidding, even when the high bidder does not have the highest value. If set too low, the auction may last too many rounds if bidders bid at the minimum level. Large increments are especially useful early in the auction when activity is high and prices are low. There is little cost to large increments early in the auction. Large increments are inefficient only when they prevent the highest valuer from placing a bid. But if prices are low, the highest valuer can easily top the high bid by the minimum increment. Inefficiencies only appear when a license is about to close and the size of the inefficiency is at most one bid increment. (Markets do not literally close license-by-license. Individual licenses "close" in the sense that there are no further bids in the market.) Thus, the auctioneer can start with a large increment and then reduce the increment as the probability of closure increases. In the nationwide auction, where all of the licenses were good substitutes, overall bid activity was an excellent measure of when licenses were about to close, so a sensible rule tied the bid increment to bid activity.

In the MTA auction, licenses in different markets are not good substitutes and there is much greater variation in prices across markets. The FCC had no way to know when markets were likely to close. Also with so many licenses, it made sense to have a single rule for setting increments across all licenses. In the standard rule, the minimum increment is the greater of a percentage increment or a per-pop increment. Initially, the percentage increment was $5 \%$ and the per-pop increment was $\$ .60$ per pop (or $\$ .02$ per MHz-pop). In this case, until the price reaches $\$ 12$ per pop, the per-pop increment would bind. Before a license receives a bid, the minimum increment is 0 . This prevents licenses worth less than $\$ .60$ per pop from going unsold.

Early in stage 2, bidders continued to bid at the minimum level, but eligibility did not drop. Hence, to speed the auction along, the percentage increment was doubled to $10 \%$ in round 31 . By round 31 , the $10 \%$ increment was greater than the per pop increment in many important markets. The fact that the percentage increment was $5 \%$ at the beginning of the auction was largely irrelevant, since early in the auction it is the per pop increment that is binding. The per-pop increment remained \$.60 per pop. The rationale for leaving the per-pop increment fixed was that several of the low-priced licenses might be near closure and this would reduce any inefficiencies on these licenses.

At the end of stage 2, the percentage increment had been cut back to $5 \%$. When stage 3 began with the same strong activity seen in the beginning of stage 2, the FCC considered whether to raise the percentage increment to $10 \%$ again. This option was rejected and with good reason. In stage 3, activity drops as bidders reduce eligibility by permanently dropping out of markets. It is precisely at this point the point when reservation prices are reached - that a modest bid increment is desired. Markets closed throughout the remainder of stage 3. This is seen in Figure 10, which shows the fraction of licenses (pop weighted) with final bids by round. Licenses did not begin to close until midway through stage 2 (about round 36). By the end of stage 2 (round 64) only $19 \%$ of the licenses had received their final bids. The remaining $81 \%$ of the licenses closed throughout stage 3 at a rapid and steady pace. Hence it was important to keep the bid increment low throughout stage 3. 
Based on similar reasoning, there is little point in dropping the bid increment late in stage 3. Toward the end of the auction, the vast majority of markets have already effectively closed and there is no way for a bidder to return to a market to take advantage of a lower increment. The lower increment then is only effective in the few markets that have yet to close. Since there is no way to predict when reservation prices may be reached in these markets, dropping the increment to $2 \%$ might greatly extend the auction (as was the case in the regional auction). The efficiency and revenue gain is likely small, since the low increment only applies to the few markets that have yet to close. Hence, it made sense to keep the increment at 5\% throughout stage 3 .

In retrospect, the MTA auction could have been sped up without much efficiency loss by adopting larger bid increments in the early rounds. Increments of $10 \%$ or $\$ 1.20$ per pop in the first thirty rounds would have shortened the auction by more than a week. These adjustments were made for the final three auctions.

In future auctions, the FCC plans to further quicken the pace by using even larger bid increments early on. A difficulty with large increments is that some licenses may be close to final prices when others are far from final prices. To avoid this problem, the FCC plans to use license specific increments, where activity is used as an indicator that the license is far from the final price and a larger increment is in order. In the C-block it was not uncommon for some licenses to have no new bids and for others to have a dozen.

\subsection{The Activity Rule Worked Well}

One potential problem with the MTA broadband auction was the fact that prices and assignments shifted substantially in stage 3 . Ideally, most of the action would take place in stage 1 and stage 2 , when the less restrictive activity requirements were in place. Bidders in the early stages have great flexibility in shifting among licenses. In stage 3 , flexibility is curtailed, increasing the possibility of inefficient assignments.

Perhaps surprisingly, the stringent stage 3 activity requirement did not pose a major obstacle to large bidders. Bidders were able to maintain eligibility through double bidding. Even without the double bid, firms bidding on several licenses were able to move among different sets of licenses, only losing an insignificant amount of eligibility. However, stage 3 does distort behavior. In each round, firms placed strategic bids to maintain eligibility and withdrawals were more common. Nonetheless, it does not appear that this strategic bidding severely reduced efficiency.

In stage 3, it is possible for the auction to effectively become a sequence of auctions from largest market to smallest as bidders drop down to smaller licenses. Bidders may not have the flexibility to make more sophisticated shifts. This hypothesis can be tested by looking at the time of final bids by license during stage 3 . There was a slight tendency for larger licenses to close earlier. However, the association is weaker when one restricts attention to stage 3 . Both the bidding behavior and the time of closure by license suggest that bidders had much more flexibility in stage 3 than in a sequence of auctions from largest to smallest.

The problems of a long stage 3 in the MTA auction were reduced in the last three auctions by adjusting the activity rule. In the C-block, the required activity in stage 1 was increased from $33 \%$ to $60 \%$ and the activity in stage 2 from $67 \%$ to $80 \%$. This forces more of the sorting to occur in stages 1 and 2 , and yet still give the bidders substantial flexibility in these early stages. In addition, the FCC reduced the stage 3 activity requirement from $100 \%$ to $95 \%$, increasing flexibility in stage 3. Similar, activity requirements were used in the MDS and SMR auctions.

A further problem with a low activity requirement is that it can increase the possibility of successful 
tacit collusion. With an activity requirement of $1 / 3$, bidders can make modest demands without incurring the cost of a loss in eligibility. Unilateral cooperative reductions in demand are possible without losing the ability to punish if reciprocal reductions are not made by others. With a $100 \%$ activity requirement, modest demands are only possible with a loss of eligibility.

\section{Conclusion}

The FCC made a bold decision in settling on the simultaneous multiple-round auction to award the PCS licenses. Although this auction form had theoretical virtues, it was unproven. The easy decision would have been to adopt a traditional design, such as a sequential oral auction. Instead, the FCC chose to innovate. After careful study, the FCC began testing and fine-tuning the design with the auction of nationwide and regional narrowband licenses. These first two auctions proved remarkably successful. The theoretical virtues of the design became practical realities. Bidders moved easily among license combinations as prices adjusted. This movement was unhampered by activity requirements in the nationwide auction and only slightly constrained in the regional auction. There was a strong tendency for prices of similar licenses to sell for similar prices. Finally, the license assignments satisfied technical efficiency. When bidders won multiple bands, the bands were adjacent; when bidders won multiple regions, the regions were adjacent and on the same band.

Armed with these early successes, the FCC pushed forward with the MTA broadband PCS auction, the largest auction ever. Although this auction did not share the early aggressive behavior seen in the narrowband auctions, revenues increased steadily throughout the auction. Despite a restrictive activity requirement in the final stage, bidders managed to shift among licenses in response to price changes and build sensible aggregations. Competition heated up in the final stage, suggesting that the auction did identify an efficient allocation through escalating prices. Nonetheless, because of bidder alliances, competition was limited in several markets. Future auctions may benefit from restricting alliances among major firms.

The C-block, MDS, and SMR auctions demonstrated the feasibility of the simultaneous multipleround auction even with hundreds of bidders and licenses. These auctions required about 80 days of bidding - a relatively short period to determine an assignment of this complexity.

The success of these auctions does not imply that alternative designs would be less successful or that success is assured in future auctions. Although the early evidence is encouraging, there is still much to learn about auctions in this complex setting. One thing is certain: the assignment of licenses by auction is a huge improvement over allocation by lottery or comparative hearings. Market competition is putting the licenses in the hands of those companies best able to use them. Firms, consumers, and taxpayers all benefit.

\section{References}

Ashenfelter, Orley (1989), "How Auctions Work for Wine and Art," Journal of Economic Perspectives, 3, 23-26.

Ausubel, Lawrence M. and Peter C. Cramton (1996), "Demand Reduction and Inefficiency in Multi-Unit Auctions," Working Paper, University of Maryland.

Ausubel, Lawrence M., Peter Cramton, R. Preston McAfee, and John McMillan (1996), "Synergies in Wireless Telephony: Evidence from the MTA Auction," Working Paper, University of Maryland. 
Avery, Christopher (1994), "Strategic Jump Bidding in an English Auction," Working Paper, Kennedy School of Government, Harvard University.

Ayres, Ian and Peter Cramton (1996), "Pursuing Deficit Reduction Through Diversity: A Case Study of How Affirmative Action at the FCC Increased Auction Competition," Stanford Law Review, forthcoming.

Ballard, Charles L., John B. Shoven, and John Whalley (1985), "General Equilibrium Computations of the Marginal Welfare Costs of Taxes in the United States," American Economic Review, 85, 128138.

Banks, Jeffrey S., John O. Ledyard, and David P. Porter (1989), "Allocating Uncertain and Unresponsive Resources: An Experimental Approach,” Rand Journal of Economics, 20, 1-22.

Bykowsky, Mark M., Robert J. Cull, and John O. Ledyard (1995), "Mutually Destructive Bidding: The FCC Auction Design Problem," Working Paper, CalTech.

Chakravorti, Bhaskar, William W. Sharkey, Yossef Spiegel, and Simon Wilkie (1995), "Auctioning the Airwaves: The Contest for Broadband PCS Spectrum," Journal of Economics and Management Strategy, 4, 345-373.

Cramton, Peter (1995), "Money Out of Thin Air: The Nationwide Narrowband PCS Auction," Journal of Economics and Management Strategy, 4, 267-343.

Engelbrecht-Wiggans, Richard and Charles M. Kahn (1995), "Multi-Unit Auctions with Uniform Prices," Working Paper, University of Illinois.

Federal Communications Commission (1994), Fifth Report and Order, FCC 94-178, Washington, DC.

Federal Communications Commission (1994), Third Report and Order, FCC 94-98, Washington, DC.

Gandal, Neil (1995), "Sequential Auctions of Interdependent Objects: Israeli Cable Television Licenses," Working Paper, Tel-Aviv University.

Maskin, Eric S. and John G. Riley (1984), "Optimal Auctions with Risk Averse Buyers,” Econometrica, $52,1473-1518$.

Maskin, Eric and John Riley (1995), “Asymmetric Auctions,” Working Paper, UCLA.

Matthews, Steven A. (1983), "Selling to Risk Averse Buyers with Unobservable Tastes," Journal of Economic Theory, 30, 370-400.

McAfee, R. Preston and John McMillan (1987), “Auctions and Bidding,” Journal of Economic Literature, 25, 699-738.

McAfee, R. Preston and John McMillan (1996), “Analyzing the Airwaves Auction," Journal of Economic Perspectives, 10, 159-176.

McAfee, R. Preston and Daniel Vincent (1993), “The Declining Price Anomaly," Journal of Economic Theory, 60, 191-212.

McMillan, John (1994), “Selling Spectrum Rights,” Journal of Economic Perspectives, 8, 145-162.

Milgrom, Paul R. (1987), “Auction Theory,” in Truman Bewley (ed), Advances in Economic Theory Fifth World Congress, Cambridge, England: Cambridge University Press. 
Milgrom, Paul (1995), Auction Theory for Privatization, forthcoming, Cambridge, England: Cambridge University Press.

Milgrom, Paul R. and Robert J. Weber (1982), “A Theory of Auctions and Competitive Bidding," Econometrica, 50, 1089-1122.

Myerson, Roger B. (1981), "Optimal Auction Design,” Mathematics of Operations Research, 6, 58-73.

Rothkopf, Michael H. and Ronald M. Harstad (1990), "Reconciling Efficiency Arguments in Taxation and Public Sector Resource Leasing," Working Paper, Rutgers University.

Rothkopf, Michael H., Ronald M. Harstad, and Yuhong Fu (1996), "When Does it Pay for a Bid Taker to Subsidize Inefficient Bidders?” Working Paper, Rutgers University.

Rothkopf, Michael H., Aleksandar Pekec, and Ronald M. Harstad (1995), "Computationally Manageable Combinatorial Auctions," Working Paper, Rutgers University.

Salant, David J. (1995), "Up in the Air: GTE's Experience in the MTA Auctions for PCS Licenses," Working Paper, Charles River Associates, Boston, MA. 
Tables

1 Final Outcome in Nationwide Narrowband PCS Auction (Round 47)

2 Final Outcome in Regional Narrowband PCS Auction (Round 105)

3 Final Outcome by Market in MTA Broadband PCS Auction (Round 112)

4 Final Outcome by Bidder in MTA Broadband PCS Auction (Round 112)

5 Bidder Types and Strategies

6 Bid Withdrawals in MTA Broadband PCS Auction

7 Price Comparison in Major Markets

8 Comparison of PCS Spectrum Auctions

9 Distribution of the Excess Bidders (Population Weighted)

Figures

1 Bidding Activity and Revenue by Round in Nationwide Auction

2 Bidding Activity and Revenue by Round in Regional Auction

3 Bidding Activity and Revenue by Round in MTA Auction

4 Bidding Activity and Revenue by Round in C-block Auction

5 Bidding Activity and Revenue by Round in MDS Auction

6 Bidding Activity and Revenue by Round in SMR Auction

7 Fraction of Current High Bidders that Win in Market in MTA Auction

8 Correlation Between Current and Final Prices in MTA Auction

9 Eligibility Ratio in MTA Auction

10 Fraction of Licenses with Final Bid (Pop Weighted) in MTA Auction 